\title{
Effect of Cross-Sectional Aspect Ratio on Rectangular FRP-Concrete-Steel Double-Skin Tubular Columns under Axial Compression
}

\author{
Bing Zhang $\mathbb{D}^{1,2}$ Xia-Min Hu, ${ }^{2}$ Wei Wei, ${ }^{2,3}$ Qian-Biao Zhang, ${ }^{2}$ Ning-Yuan Zhang, \\ and Yi-Jie Zhang ${ }^{2}$ \\ ${ }^{1}$ School of Civil and Environmental Engineering, Harbin Institute of Technology (Shenzhen), Shenzhen, China \\ ${ }^{2}$ College of Civil Engineering, Nanjing Tech University, Nanjing, China \\ ${ }^{3}$ Powerchina Real Estate Group Ltd., Beijing, China
}

Correspondence should be addressed to Bing Zhang; zhangb@njtech.edu.cn

Received 23 October 2019; Accepted 12 March 2020; Published 27 May 2020

Guest Editor: Tianyu Xie

Copyright (c) 2020 Bing Zhang et al. This is an open access article distributed under the Creative Commons Attribution License, which permits unrestricted use, distribution, and reproduction in any medium, provided the original work is properly cited.

Hybrid FRP-concrete-steel double-skin tubular columns (hybrid DSTCs) are novel hollow columns consisting of an outer FRP tube, an inner steel tube, and the concrete between the two tubes. Hybrid DSTCs possess important advantages, such as excellent corrosion resistance as well as remarkable seismic resistance. However, existing studies are mainly focused on hybrid DSTCs with a circular cross section or a square cross section. When a column is subjected to different load levels in the two horizontal directions, a rectangular column is preferred as it can provide different bending stiffness and moment capacity around its two axes of symmetry. This paper presents an experimental study on rectangular DSTCs with a particular focus on the effect of the cross-sectional aspect ratio (i.e., the ratio of the breadth to the width of the rectangular cross section). The effect of the cross-sectional shape of the inner steel tube (i.e., both elliptical and rectangular inner steel tubes were used) and the effect of FRP tube thickness were also investigated experimentally. Experimental results show that a larger aspect ratio will have no negative effect on the confinement effect in rectangular DSTCs; a rectangular DSTC with a larger aspect ratio generally has a larger ultimate axial strain and a higher axial stress at the ultimate axial strain; rectangular DSTCs with an elliptical steel tube generally have better performance than corresponding specimens with a rectangular steel tube. An existing model, which was developed based on a model for rectangular FRP-confined concrete columns and a model for circular DSTCs, is verified using the test results of the present study. The model generally provides close predictions for the peak axial stress of the confined concrete but yields conservative predictions for the ultimate axial strain for rectangular DSTCs.

\section{Introduction}

In the field of civil engineering, FRP composites have found increasing applications for the retrofitting of existing structures as well as the construction of new structures [1-3]. FRP composites are particularly attractive for use in combination with traditional construction materials (i.e., concrete, steel, and timber) to create novel hybrid structures [4]. Hybrid FRP-concrete-steel double-skin tubular columns (hybrid DSTCs) are novel hollow columns that combine concrete, steel, and FRP together in an optimal manner [5]. Hybrid DSTCs have an outer FRP tube, an inner steel tube, and a layer of concrete between the two tubes (Figure 1). The inner steel tube is the primary longitudinal reinforcement, whereas the outer FRP tube provides confinement to the concrete. The two tubes could be used as the in situ formwork for the concrete casting, thus saving the construction cost and advancing the construction schedule. Hybrid DSTCs are quite suitable for structural members in harsh environments due to their excellent corrosion resistance, which is enabled by the use of the outer FRP tube. Hybrid DSTCs are also particularly attractive for use in seismic regions due to their excellent energy dissipation ability under earthquake loading [6,7].

Teng et al. [5] presented the first-ever experimental study on hybrid DSTCs under axial compression to explain the 


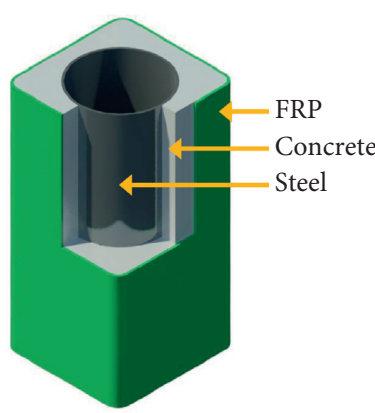

(a)

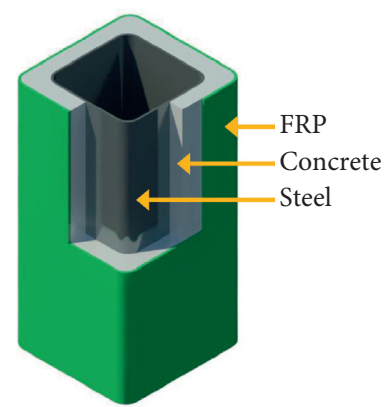

(b)

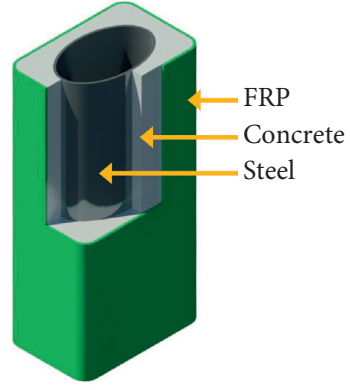

(c)

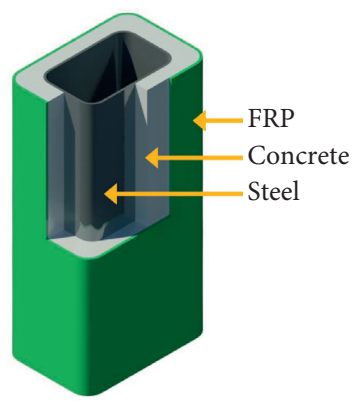

(d)

Figure 1: Cross section of square and rectangular DSTCs. (a) Square DSTCs with a circular steel tube, (b) square DSTCs with a square steel tube, (c) rectangular DSTCs with an elliptical steel tube, and (d) rectangular DSTCs with a rectangular steel tube.

rationale of hybrid DSTCs and to demonstrate their advantages. Han et al. [8] commented that this new member form "combines the advantages of all three constituent materials and those of the structural form of double-skin tubular columns." Hollaway [9] introduced this new form of hybrid members in detail in his review paper and commented that it "is relatively easy to construct and is highly resistant to corrosion and earthquakes." In recent years, hybrid DSTCs have already received extensive research attention. Existing studies are mainly focused on hybrid DSTCs under loading conditions as follows: (1) monotonic axial compression [5, 10-12], which confirms that the concrete is confined effectively by the steel tube and the FRP tube, leading to a ductile behavior; (2) cyclic axial compression $[13,14]$, which shows that the loading history has an accumulative effect on the stress-strain response of repeated unloading/reloading cycles; (3) eccentric compression $[15,16]$, which indicates that the axial load capacity decreases with the increase of load eccentricity; (4) combined axial compression and cyclic lateral loading $[6,7]$, which demonstrates that hybrid DSTCs possess excellent ductility under cyclic lateral loading; and (5) impact loading $[17,18]$, which displays the excellent energy dissipation ability of hybrid DSTCs. Existing studies, however, are mostly focused on hybrid DSTCs with a circular cross section (i.e., the cross section of the outer FRP tube is circular); $[5,8-18]$ and hybrid DSTCs with a square cross section (i.e., the cross section of the outer FRP tube is square) [6, 19-22]. Although circular columns and square columns are attractive as bridge piers, rectangular columns are preferred if such columns are subjected to different load levels in the two horizontal directions (Figure 1). Rectangular DSTCs could be designed to provide different bending stiffness and moment capacity around the two axes of symmetry according to the engineering requirements [23]. Rectangular FRP-confined concrete columns have received extensive research attention in the last decade [24-30], but experimental research on rectangular DSTCs is rather rare. To the best knowledge of the authors, there is only one experimental study on rectangular DSTCs subjected to axial compression. In Cavill and Yu's [31] study, the effect of the aspect ratio of the rectangular cross section was not investigated. All rectangular DSTCs had a breadth of $185 \mathrm{~mm}$, a width of $105 \mathrm{~mm}$, and a height of $370 \mathrm{~mm}$, and two circular steel tubes were used for each specimen. Cavill and $\mathrm{Yu}$ [31] confirmed the concrete in rectangular DSTCs was effectively confined by the FRP tube and the steel tube, leading to a very ductile response.

The present study extends the existing work to rectangular DSTCs subjected to axial compression with a particular focus on the effect of the aspect ratio, which is the ratio of the breadth (the longer side) to the width (the shorter side) of the rectangular cross section. The effect of the crosssectional shape of the inner steel tube (i.e., both rectangular and elliptical inner steel tubes were used) and the effect of the FRP tube thickness are also investigated experimentally. Rectangular FRP-confined solid concrete columns are fabricated and tested for comparison with rectangular DSTCs.

\section{Experimental Program}

2.1. Specimen Details. In the present study, rectangular specimens with four types of cross-sectional aspect ratios were fabricated and tested. These specimens all had a height of $600 \mathrm{~mm}$ and a corner radius of $30 \mathrm{~mm}$ on the outer rectangular cross section. Specimen details are summarized in Table 1, and the cross-sectional configurations are shown in Figure 2. For all specimens, the breadth $l$ of the outer rectangular cross section was $300 \mathrm{~mm}$, while the width $w$ was $300 \mathrm{~mm}, 250 \mathrm{~mm}, 200 \mathrm{~mm}$, or $150 \mathrm{~mm}$, leading to four different cross-sectional aspect ratios $l / w$ (i.e., 1.0, 1.2, 1.5, or 2.0). These specimens with an aspect ratio $l / w$ of 1.0 are square DTSCs. As shown in Table 1 and Figure 2, these specimens could be divided into three groups based on their cross-sectional configurations: (1) group 1, rectangular DSTCs with an elliptical inner steel tube (referred to as REDSTCs); (2) group 2, rectangular DSTCs with a rectangular inner steel tube (referred to as RR-DSTCs); and (3) group 3, rectangular FRP-confined solid concrete columns (referred to as R-CFFTs). For RE-DSTCs in group-1, four types of elliptical steel tubes were used, which had the same major axis $2 a_{s}$ (i.e., $204 \mathrm{~mm}$ ), but four different minor axes $2 b_{s}$ (i.e., $204 \mathrm{~mm}, 170 \mathrm{~mm}, 136 \mathrm{~mm}$, and $102 \mathrm{~mm}$ ) (Table 2 and Figures 2 and 3). For RR-DSTCs in group 2, four types of rectangular steel tubes were used, which had the same corner radius of $20 \mathrm{~mm}$ and the same breadth $l_{s}$ for the steel 
TABle 1: Specimen details.

\begin{tabular}{|c|c|c|c|c|c|c|}
\hline \multirow{2}{*}{ Specimen type } & \multirow{2}{*}{ Specimen name } & \multicolumn{3}{|c|}{ Sectional dimensions } & \multirow{2}{*}{ Steel tube type } & \multirow{2}{*}{ FRP layers/thickness $(\mathrm{mm})$} \\
\hline & & $l(\mathrm{~mm})$ & $w(\mathrm{~mm})$ & $l / w$ & & \\
\hline \multirow{6}{*}{ RE-DSTCs } & RC1-ec1-F6 & 300 & 300 & 1.0 & ec1 & 6 layers/2.10 \\
\hline & RC2-ec2-F3 & 300 & 250 & 1.2 & ec2 & 3 layers/1.05 \\
\hline & RC2-ec2-F6 & 300 & 250 & 1.2 & ec2 & 6 layers/2.10 \\
\hline & RC3-ec3-F3 & 300 & 200 & 1.5 & ec3 & 3 layers/1.05 \\
\hline & RC3-ec3-F6 & 300 & 200 & 1.5 & ec3 & 6 layers/2.10 \\
\hline & RC4-ec4-F6 & 300 & 150 & 2.0 & ec4 & 6 layers/2.10 \\
\hline \multirow{6}{*}{ RR-DSTCs } & RC1-rc1-F6 & 300 & 300 & 1.0 & $\mathrm{rc1}$ & 6 layers/2.10 \\
\hline & $\mathrm{RC} 2-\mathrm{rc} 2-\mathrm{F} 3$ & 300 & 250 & 1.2 & $\mathrm{rc} 2$ & 3 layers/1.05 \\
\hline & $\mathrm{RC} 2-\mathrm{rc} 2-\mathrm{F} 6$ & 300 & 250 & 1.2 & $\mathrm{rc} 2$ & 6 layers $/ 2.10$ \\
\hline & RC3-rc3-F3 & 300 & 200 & 1.5 & $\mathrm{rc3}$ & 3 layers/1.05 \\
\hline & RC3-rc3-F6 & 300 & 200 & 1.5 & $\mathrm{rc} 3$ & 6 layers/2.10 \\
\hline & RC4-rc4-F6 & 300 & 150 & 2.0 & $\mathrm{rc} 4$ & 6 layers/2.10 \\
\hline \multirow{6}{*}{ R-CFFTs } & RC1-F6 & 300 & 300 & 1.0 & - & 6 layers/2.10 \\
\hline & $\mathrm{RC} 2-\mathrm{F} 3$ & 300 & 250 & 1.2 & - & 3 layer/1.05 \\
\hline & RC2-F6 & 300 & 250 & 1.2 & - & 6 layers/2.10 \\
\hline & RC3-F3 & 300 & 200 & 1.5 & - & 3 layers/1.05 \\
\hline & RC3-F6 & 300 & 200 & 1.5 & - & 6 layers/2.10 \\
\hline & RC4-F6 & 300 & 150 & 2.0 & - & 6 layers/2.10 \\
\hline
\end{tabular}

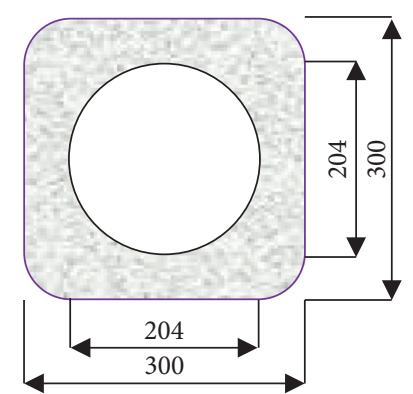

(a)

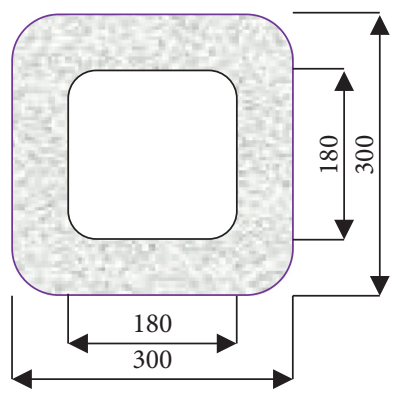

(e)

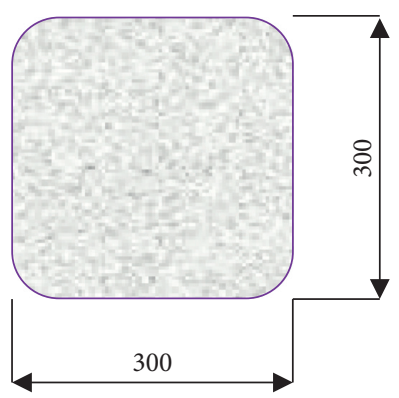

(i)

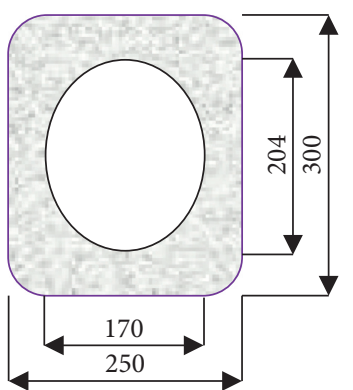

(b)

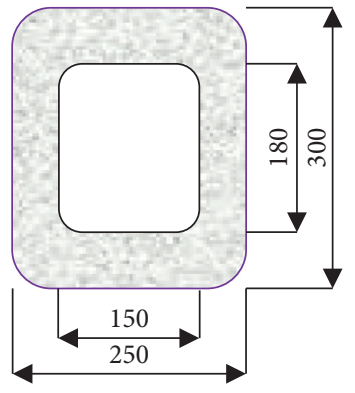

(f)

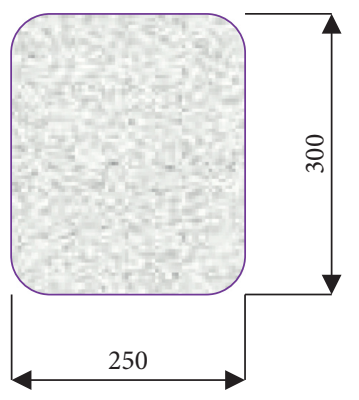

(j)

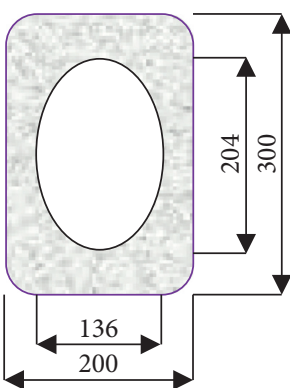

(c)

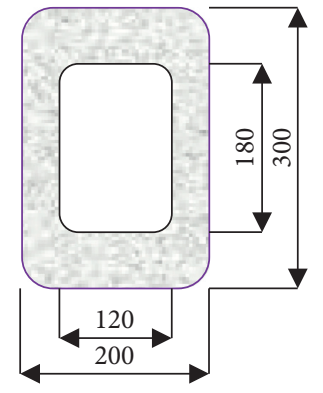

(g)

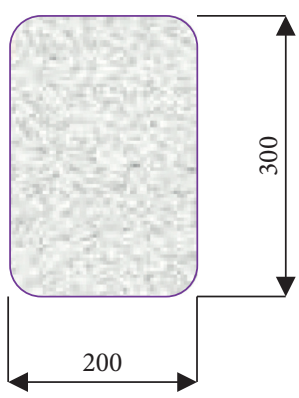

(k)

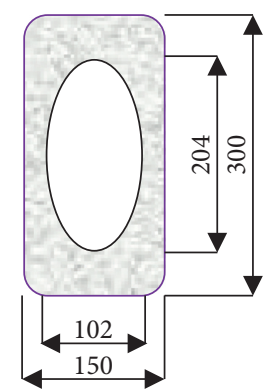

(d)

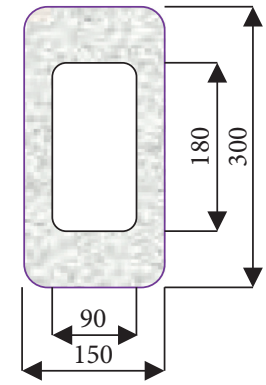

(h)

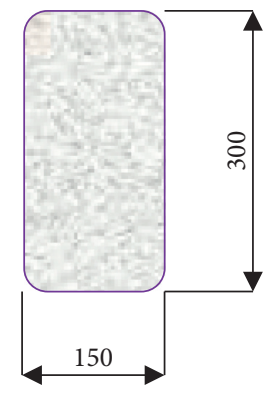

(1)

Figure 2: Cross-sectional configurations. (a) RC1-ec1-F6, (b) RC2-ec2-F6 RC2-ec2-F3, (c) RC3-ec3-F6 RC3-ec3-F3, (d) RC4-ec4-F6, (e) RC1-rc1-F6, (f) RC2-rc2-F6 RC2-rc2-F3, (g) RC3-rc3-F6 RC3-rc3-F3, (h) RC4-rc4-F6, (i) RC1-F6, (j) RC2-F6 RC2-F3, (k) RC3-F6 RC3-F3, and (l) RC4-F6. 
Table 2: Details of elliptical steel tubes.

\begin{tabular}{|c|c|c|c|c|c|c|}
\hline Type of steel tube & $2 a_{s}(\mathrm{~mm})$ & $2 b_{s}(\mathrm{~mm})$ & $a_{s} / b_{s}$ & $f_{y}(\mathrm{MPa})$ & $E_{s}(\mathrm{GPa})$ & $f_{u}(\mathrm{MPa})$ \\
\hline ec1 & 204 & 204 & 1.0 & \multirow{4}{*}{302.6} & \multirow{4}{*}{201.0} & \multirow{4}{*}{441} \\
\hline ec2 & 204 & 170 & 1.2 & & & \\
\hline ec3 & 204 & 136 & 1.5 & & & \\
\hline ec4 & 204 & 102 & 2.0 & & & \\
\hline
\end{tabular}

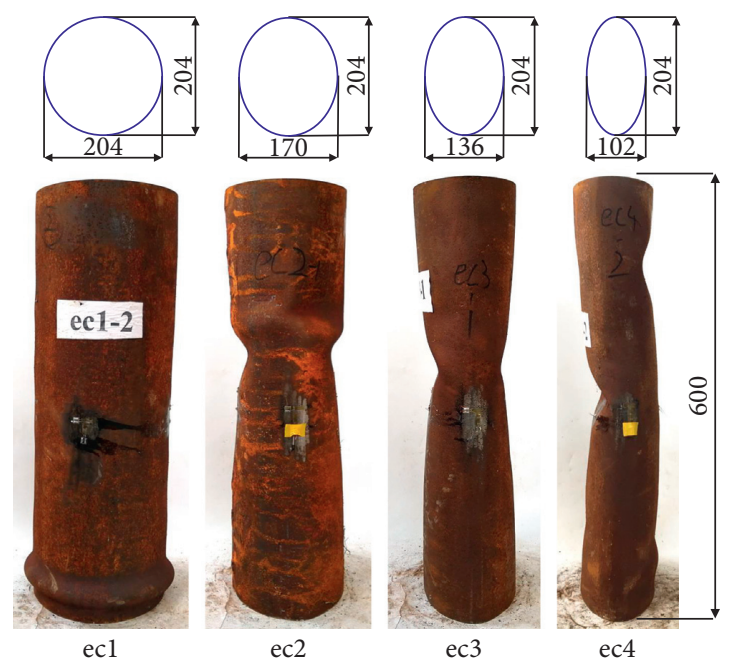

(a)

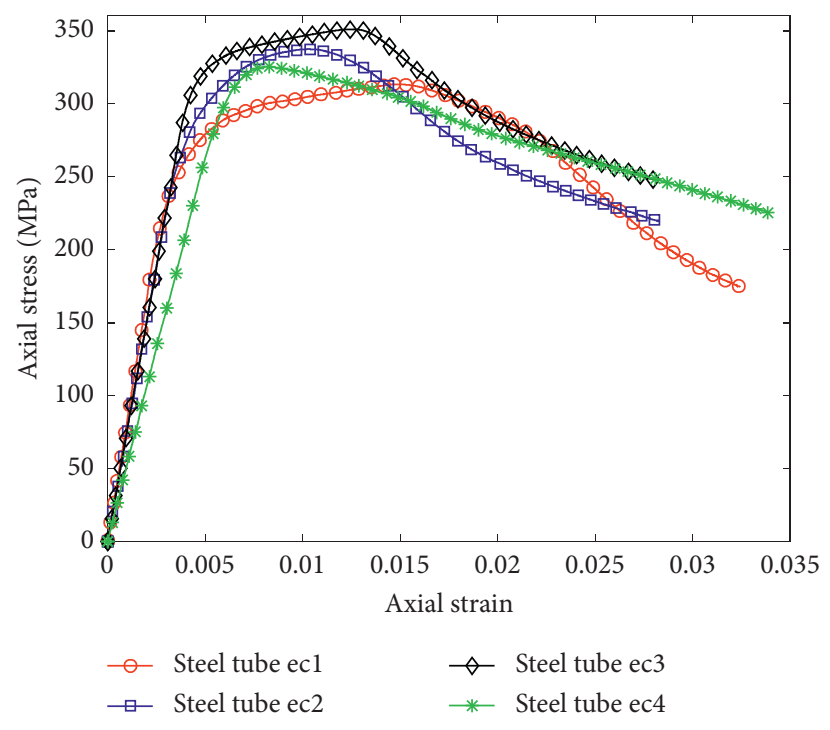

(b)

FIgURe 3: Axial compression test of elliptical hollow steel tubes. (a) Elliptical hollow steel tubes and (b) axial stress-axial strain curves.

rectangular cross section (i.e., $180 \mathrm{~mm}$ ) but four different widths $w_{s}$ (i.e., $180 \mathrm{~mm}, 150 \mathrm{~mm}, 120 \mathrm{~mm}$, and $90 \mathrm{~mm}$ ) (Table 3 and Figures 2 and 4). Compared with R-CFFTs, rectangular DSTCs can save concrete significantly due to the inner void, which could be indicated by the void area ratio (i.e., the ratio of the concrete void area to the area of the gross rectangular concrete section). These rectangular DSTCs were designed to have the same void area ratio of 0.46 , thus saving around $46 \%$ concrete compared with rectangular R-CFFTs in the present study.

As shown in Table 1, each specimen was given a name for ease of reference: (1) "RC1," "RC2," "RC3," and "RC4" are used to indicate the cross-sectional aspect ratio to be "1.0," "1.2," "1.5," and "2.0," respectively; (2) "ec" or " $r c$ " is used to represent the cross section of the inner steel tube to be elliptical or rectangular, followed by a digit to indicate the type of the steel tube as shown in Tables 2 and 3; (3) the letter " $F$ " and one digit are representing the fiber sheet layers of the FRP tube. The nominal thickness of each layer fiber sheet was $0.35 \mathrm{~mm}$, leading to two FRP tube thicknesses for the present study (i.e., 3-layer FRP tube with a nominal thickness of $1.05 \mathrm{~mm}$ and 6-layer FRP tube with a nominal thickness of $2.10 \mathrm{~mm}$ ) (Table 1). For each rectangular DSTC with a rectangular inner steel tube, there was a corresponding rectangular DSTC with an elliptical inner steel tube for comparison, which had the same FRP tube thickness and the same void area ratio as the former one (e.g., RC2rc2-F6 and RC2-ec2-F6 are a pair of rectangular DSTCs for comparison). All steel tubes in the present study had the same thickness (i.e., $4.5 \mathrm{~mm}$ ). The FRP tube of all specimens was formed by wrapping continuous unidirectional glass/ epoxy laminates on the hardened concrete surface with the fibers oriented in the hoop direction. For each FRP tube, there was an overlapping zone spanning a circumferential distance of around $150 \mathrm{~mm}$ along the longer side of the rectangular cross section (Figure 5). Additional FRP strips with a width of $40 \mathrm{~mm}$ were provided near the two ends of the specimens to prevent premature failure there. A thin layer of high-strength plaster was used for capping to achieve a flat end before the compressive test.

\subsection{Material Properties}

2.2.1. Concrete. In order to guarantee the casting quality of the concrete, self-compacting concrete (SCC) was adopted for the present study. Plain concrete cylinders with a height of $300 \mathrm{~mm}$ and a diameter of $150 \mathrm{~mm}$ were tested following ASTM C39/C39M [32]. A displacement-controlled loading rate of $0.18 \mathrm{~mm} / \mathrm{min}$ was adopted for the testing of concrete cylinders. The elastic modulus $E_{c}$, the peak stress $f_{\text {co }}^{\prime}$, and the axial strain at the peak stress $\varepsilon_{\text {co }}$ averaged from these concrete cylinder tests are $33.6 \mathrm{GPa}, 50.4 \mathrm{MPa}$, and $0.26 \%$, respectively.

2.2.2. FRP. Tensile tests were conducted on flat coupons following ASTM D3039 [33] to obtain the material 
TABLE 3: Details of rectangular steel tubes.

\begin{tabular}{|c|c|c|c|c|c|c|}
\hline Type of steel tube & $l_{s}(\mathrm{~mm})$ & $w_{s}(\mathrm{~mm})$ & $l_{s} / w_{s}$ & $f_{y}(\mathrm{MPa})$ & $E_{s}(\mathrm{GPa})$ & $f_{u}(\mathrm{MPa})$ \\
\hline $\mathrm{rcl}$ & 180 & 180 & 1.0 & \multirow{4}{*}{308.0} & \multirow{4}{*}{200.3} & \multirow{4}{*}{459} \\
\hline $\mathrm{rc} 2$ & 180 & 150 & 1.2 & & & \\
\hline $\mathrm{rc} 3$ & 180 & 120 & 1.5 & & & \\
\hline $\mathrm{rc} 4$ & 180 & 90 & 2.0 & & & \\
\hline
\end{tabular}

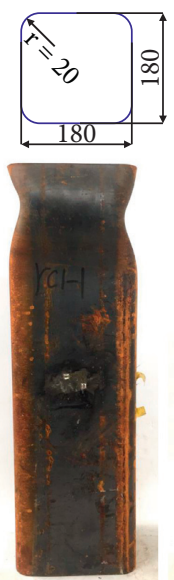

$\mathrm{rcl}$
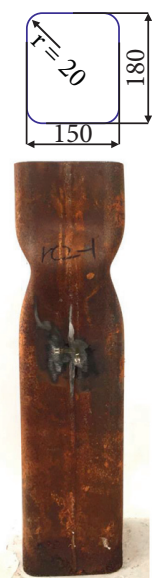

$\mathrm{rc2}$
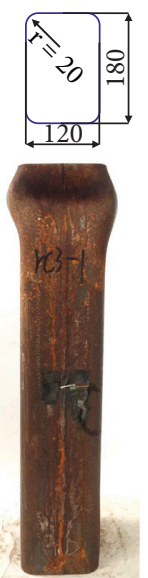

rc3

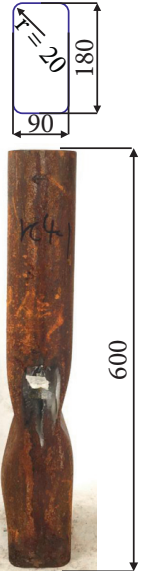

$\mathrm{rc4}$

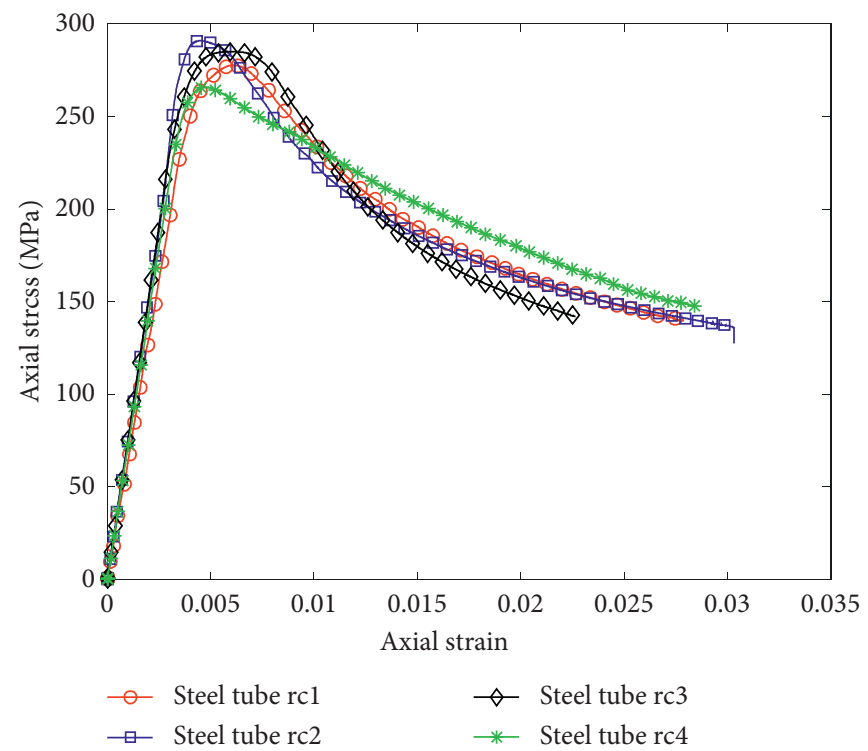

(b)

FIgURE 4: Axial compression test of rectangular hollow steel tubes. (a) Rectangular hollow steel tubes and (b) axial stress-axial strain curves.

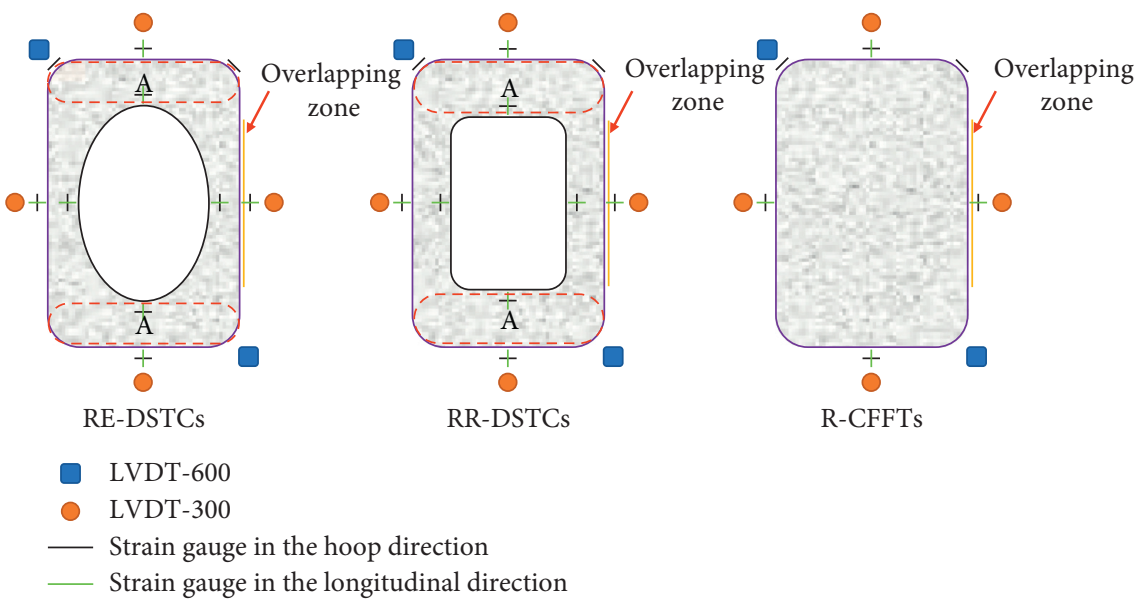

(a)

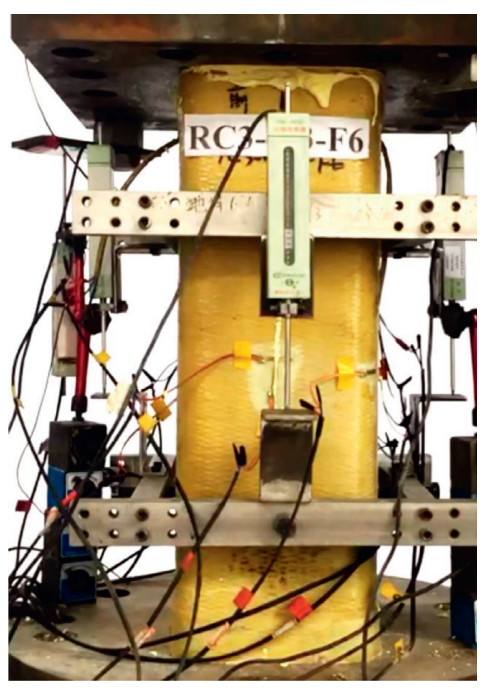

(b)

Figure 5: Experimental setup and instrumentation. (a) Planar view of strain gauges and LVDTs and (b) experimental setup.

properties of the FRP tube. The FRP coupon, which contained two layers of fiber sheets, was fabricated using the same wet-layup technique as the FRP tube for rectangular DSTCs. The elastic modulus $E_{\text {frp }}$, the ultimate strength, and the ultimate strain averaged from these FRP flat coupons are $80.1 \mathrm{GPa}, 1836.2 \mathrm{MPa}$, and $2.29 \%$, respectively.
2.2.3. Steel Tube. As shown in Tables 2 and 3, there were four types of elliptical steel tubes and four types of rectangular steel tubes in the present study. All rectangular steel tubes were fabricated using the same batch of raw materials, whereas all elliptical steel tubes were manufactured using another batch of raw materials. All these steel tubes were 
manufactured following these four steps: (1) cutting the flat steel plate to designed dimensions; (2) bending the flat steel plate to form half part of a steel tube; (3) welding two identical half parts together by two longitudinal welds; and (4) milling the two ends of each steel tube to achieve flat ends which are perpendicular to its axis.

Tensile tests on steel coupons were conducted following BS 18 [34] for elliptical steel tubes and rectangular steel tubes, respectively. Test results showed the tensile stressstrain curves of these steel coupons had a long yield plateau and then a hardening branch before the final rupture. The average elastic modulus $E_{s}$, the average yield stress $f_{y}$, and the average ultimate tensile strength $f_{u}$ are shown in Tables 2 and 3 for elliptical and rectangular steel tubes, respectively. In addition, for each type of these steel tubes, two hollow steel tubes, which had the same height as those used in rectangular DSTCs (i.e., $600 \mathrm{~mm}$ ), were tested under monotonic axial compression. Four LVDTs were installed to measure the overall axial shortening of each steel tube. The failed steel tubes after axial compression tests and the axial stress-axial strain curves are all shown in Figures 3 and 4, with the axial strain being obtained from LVDTs. All steel tubes suffered severe buckling after the axial compression test.

\subsection{Experimental Setup and Instrumentation. Figure 5 shows} the experimental setup and instrumentation for all specimens. Six LVDTs were installed to measure the axial deformation of each specimen. Of the six LVDTs, four (i.e., LVDT-300) were used to measure the shortening of the $300 \mathrm{~mm}$ midheight region, while the other two (i.e., LVDT600) were used to measure the total shortening of the specimens. For the outer FRP tube, four hoop strain gauges and four axial strain gauges (gauge length $=20 \mathrm{~mm}$ ) were installed at the midpoint on each side of the rectangular cross section, while two additional hoop strain gauges were attached at the corner of the rectangular FRP tube. At the midheight of the inner steel tube, four hoop strain gauges and four axial strain gauges with a gauge length of $10 \mathrm{~mm}$ were installed and distributed evenly as shown in Figure 5. A large column testing facility with a maximum capacity of $10,000 \mathrm{kN}$ was used to conduct axial compression tests with a displacement control rate of $0.36 \mathrm{~mm} / \mathrm{min}$. All the test data, including strains, loads, and displacements, were recorded simultaneously by a data acquiring system.

\section{Test Results and Discussion}

3.1. General. At the initial stage of the loading test, readings of the four axial strains on the FRP tube were quite uniform, and there was no obvious phenomenon on the FRP tube. When the axial strain readings exceeded around $0.30 \%$, a loud noise emitted from the specimen and a substantial load drop/fluctuation occurred simultaneously, suggesting that severe damage had occurred in the concrete, which was mainly due to the insufficient confinement provided by the rectangular FRP tube. As the loading process progressed, the hoop strain readings of the two strain gauges at the FRP tube corner generally increased faster compared with other hoop strain gauges, indicating the FRP tube provided more effective confinement at the corner of the FRP tube. Noticeable damages were then observed on the outer surface of the FRP tube, which were generally at the corner or close to the corner of the rectangular cross section. At the final stage of the loading test, the progressive snapping noise of fibers was noticed. Finally, the explosive rupture of the FRP tube occurred associated with a big rupture noise.

After the test, the damage of the FRP tube and the inner steel tube was carefully examined (Figure 6). The damage of the FRP tube, which was mainly due to the hoop tension induced by the dilation of the inner concrete, was generally localized at the corner of the rectangular cross section. As expected, the concrete also suffered severe crushing at the location of the FRP rupture. Severe inward deformation and local buckling, which was generally close to the localized rupture of the FRP tube, was observed for both elliptical and rectangular steel tubes.

3.2. Axial Load-Axial Strain Curves. As the axial strain gauges were on the outer surface of the FRP tube or the inner steel tubes, their readings may not closely reflect the strain state of the confined concrete, especially after the development of significant localized damage on the FRP tube. The axial strain obtained from the LVDTs covers the full height of the specimen (i.e., LVDT-600) may not reflect the strain state of the confined concrete, especially at the early stage of the axial compression as there may be initial gaps between the loading plates and the two ends of the specimen. In this paper, the axial strain found from LVDT-300, which reflects the average axial strain of the midheight $300 \mathrm{~mm}$ region, is used to represent the axial strain of these specimens.

Axial load-axial strain curves of all specimens are shown in Figure 7 in three groups. As shown in Figure 7(c), the axial load-axial strain curves of R-CFFTs have an initial linear ascending branch and then a severe axial load drop at the axial strain of around $0.30 \%$, followed by an ascending branch until the final failure. For RR-DSTCs (Figure 7(b)), the axial load drop at the axial strain of around $0.30 \%$ is much smaller than the corresponding R-CFFTs, whereas corresponding RE-DSTCs have only small axial load fluctuation (Figure 7(a)). The sudden axial load drop/fluctuation was due to the insufficient confinement of rectangular FRP tubes. The existence of the inner steel tube in rectangular DSTCs mitigates the sudden axial load drop as the concrete is confined by both tubes, and the steel tube also contributes directly to the axial load of rectangular DSTCs.

3.3. Key Test Results. For R-CFFTs, the average axial stress of the confined concrete is found as the load resisted by the concrete divided by the cross-sectional area of the concrete. As mentioned before, the FRP tube had fibers oriented only in the hoop direction. Therefore, the direct load contribution of the FRP tube is ignored for all specimens. For rectangular DSTCs, the direct load contribution of the inner steel tube should be considered. The load resisted by the concrete in rectangular DSTCs is assumed to be equal to the load resisted by the specimen subtracted by the load resisted by the inner steel tube at the same axial strain. The load carried 


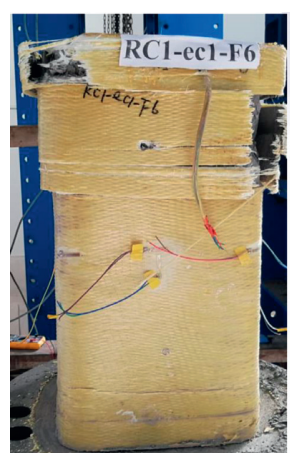

(a)

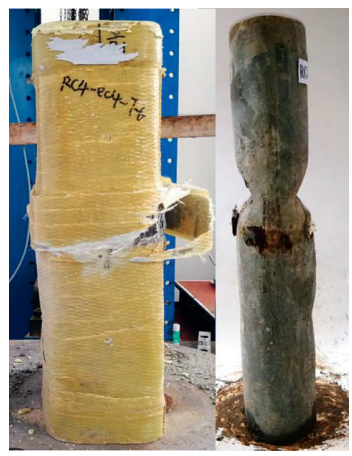

(d)

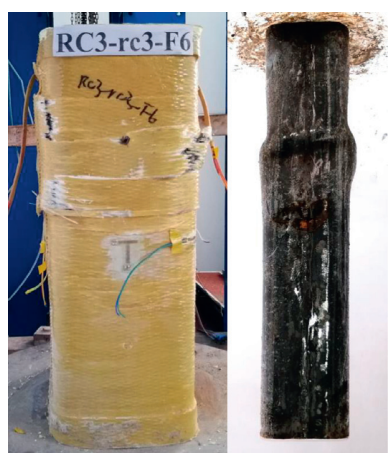

(g)

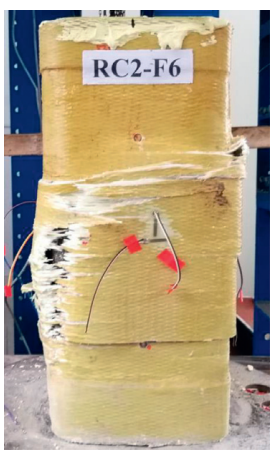

(j)
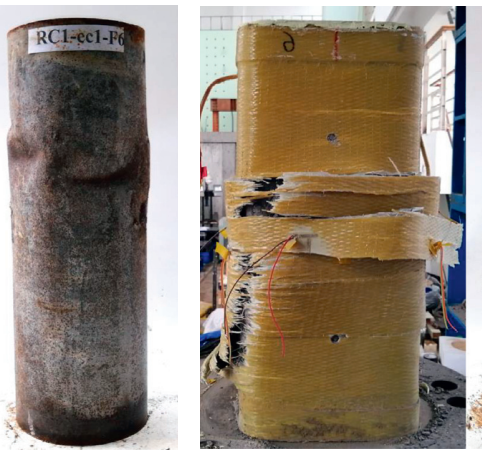

(b)

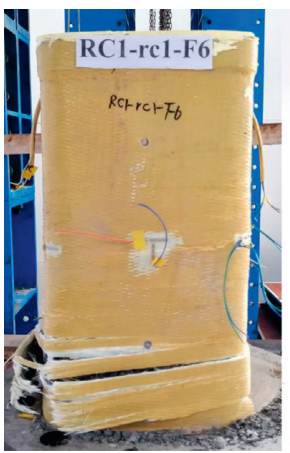

(e)

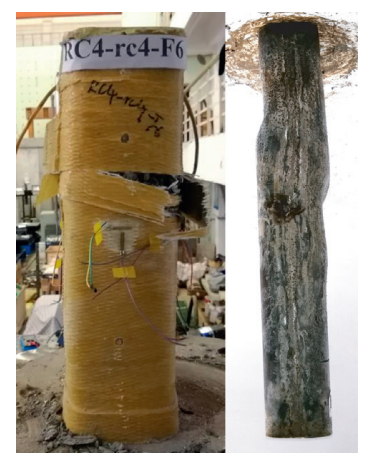

(h)

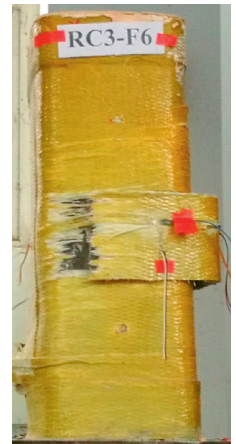

(k)

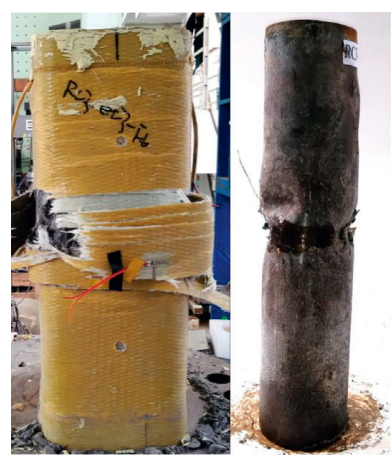

(c)

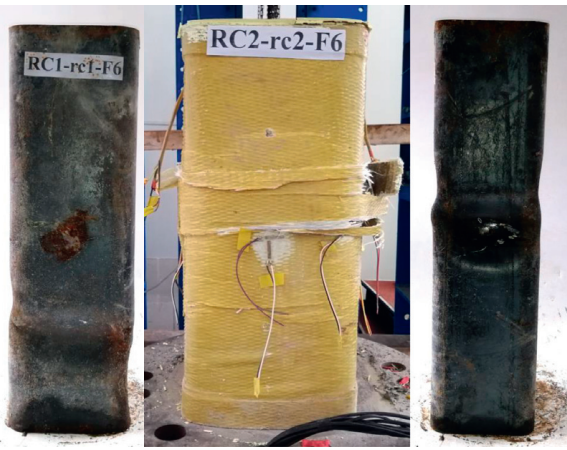

(f)

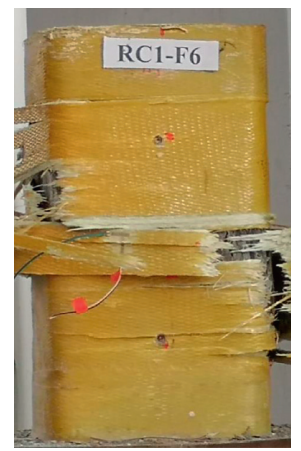

(i)

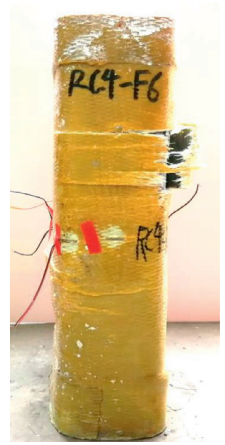

(1)

FIGURE 6: Typical failed specimens after test. (a) RC1-ec1-F6, (b) RC2-ec2-F6, (c) RC3-ec3-F6, (d) RC4-ec4-F6, (e) RC1-rc1-F6, (f) RC2-rc2F6, (g) RC3-rc3-F6, (h) RC4-rc4-F6, (i) RC1-F6, (j) RC2-F6, (k) RC3-F6, and (l) RC4-F6.

by the inner steel tube was assumed to be the same as the hollow steel tube under axial compression in Figures 3 and 4. The axial loads of the specimen, the concrete, and the steel tube are illustrated for typical rectangular DSTCs in Figure 8.
The method used above may introduce some errors to the axial stress of the confined concrete in rectangular DSTCs, which is believed to be small before the severe buckling of the inner steel tube. 


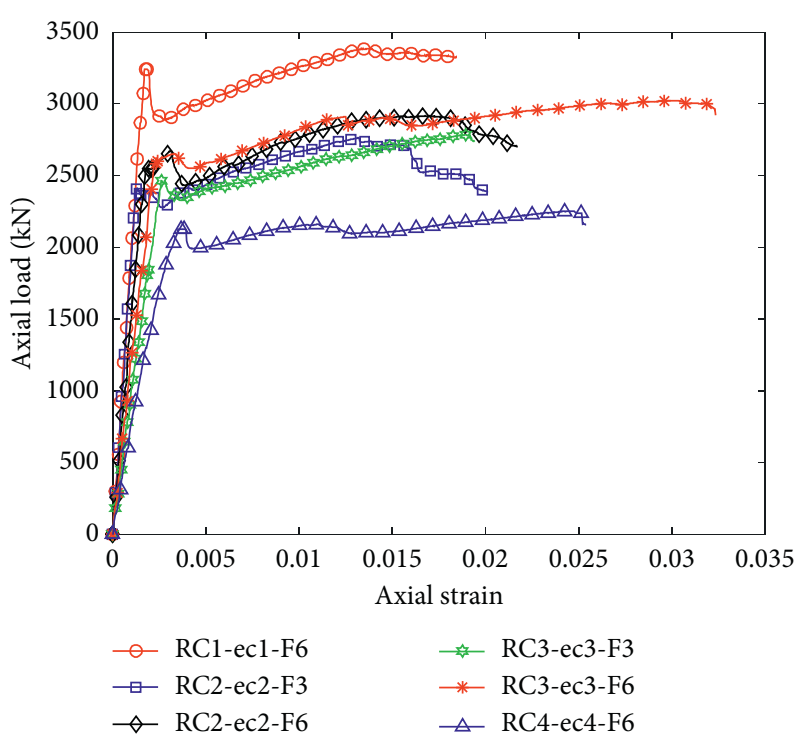

(a)

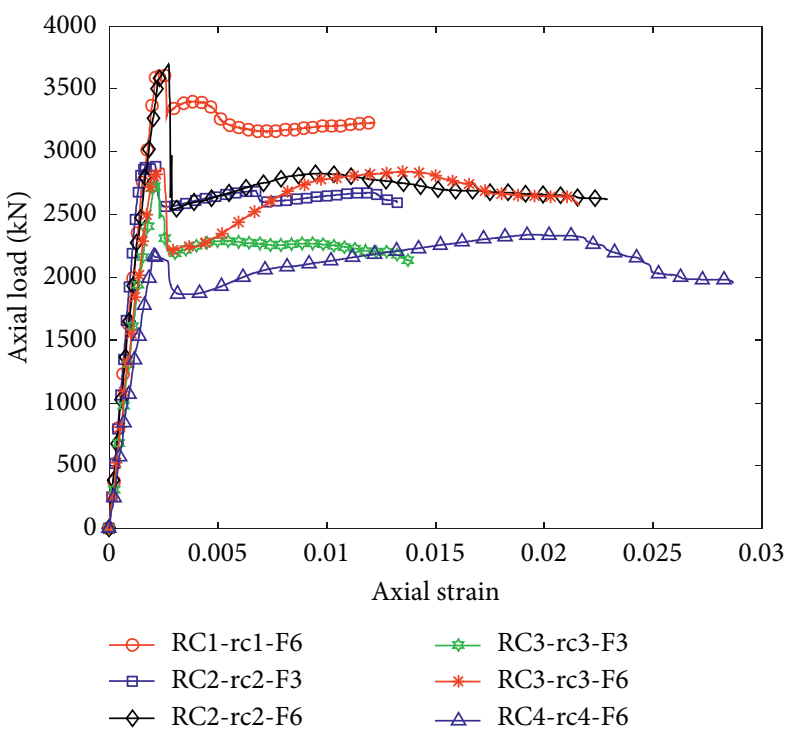

(b)

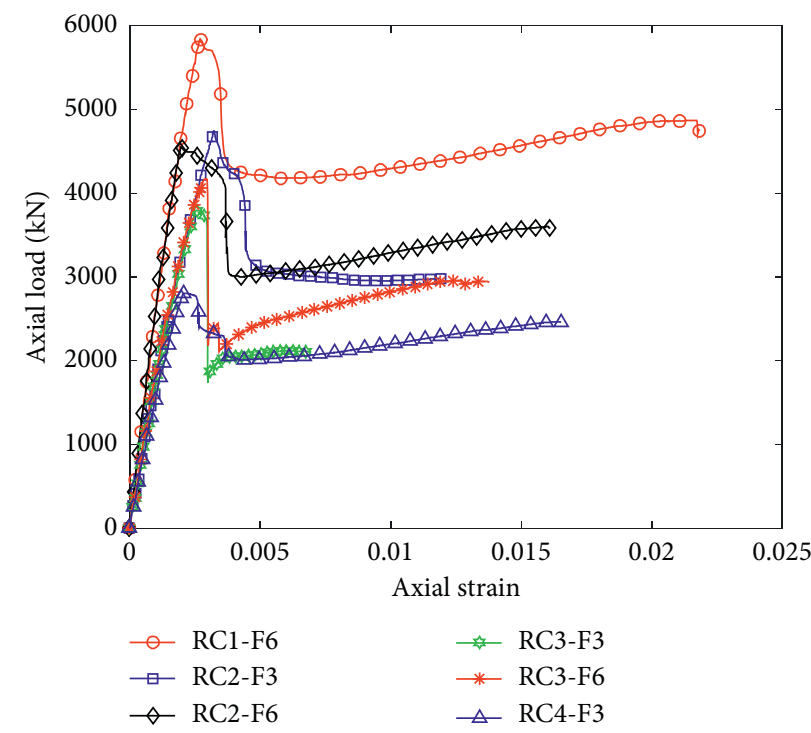

(c)

Figure 7: Axial load-axial strain curves. (a) RE-DSTCs, (b) RR-DSTCs, and (c) R-FCSCs.

The key test results of all specimens are summarized in Table 4 . In this table, $P_{\max }$ is the peak axial load of the specimen; $f_{\mathrm{cc}}$ is the peak axial stress of the confined concrete; $\varepsilon_{\mathrm{cu}}$ is the ultimate axial strain of the specimen when the FRP tube ruptured; $\varepsilon_{\text {hrup }}$ is the rupture strain of FRP tube averaged from the hoop strain gauges outside of the overlapping zone; and $f_{\mathrm{cc}} / f_{\mathrm{co}}$ and $\varepsilon_{\mathrm{cu}} / \varepsilon_{\mathrm{co}}$ are the strength enhancement ratio and the strain enhancement ratio of the confined concrete.

3.4. Effect of Cross-Sectional Aspect Ratio. As shown in Figure 9, the axial stress-strain curves of three groups of specimens are compared to evaluate the effect of the crosssectional aspect ratio. As shown in Figure 9(c), all R-CFFTs exhibit axial stress-strain curves with an ascending branch and a sudden stress drop at the axial strain of around $0.30 \%$, followed by an ascending branch until the final failure. The axial stress at the ultimate axial strain is, however, much lower than the axial stress at the axial strain of around $0.30 \%$. As indicated in Table 4, the average strength enhancement ratio $f_{\mathrm{cc}} / f_{\mathrm{co}}$ of these four specimens in Figure $9(\mathrm{c})$ is almost the same (i.e., 1.3), while specimen RC1-F6 had the largest strain enhancement ratio $\varepsilon_{\mathrm{cu}} / \varepsilon_{\mathrm{co}}$. Although these specimens in Figure 9(c) had different cross-sectional aspect ratios, the axial stress-strain curves of R-CFFTs show a good agreement with each other. As shown in Figure 9(b), similar to R-FCSCs, all RR-DSTCs exhibited a linear ascending branch and followed by a stress drop at the axial strain of around $0.30 \%$. The axial stress is then stabilized for specimens RC1rc1-F6 and RC2-rc2-F6. In contrast, the axial stress for specimens RC3-rc3-F6 and RC4-rc4-F6 recovered with an 


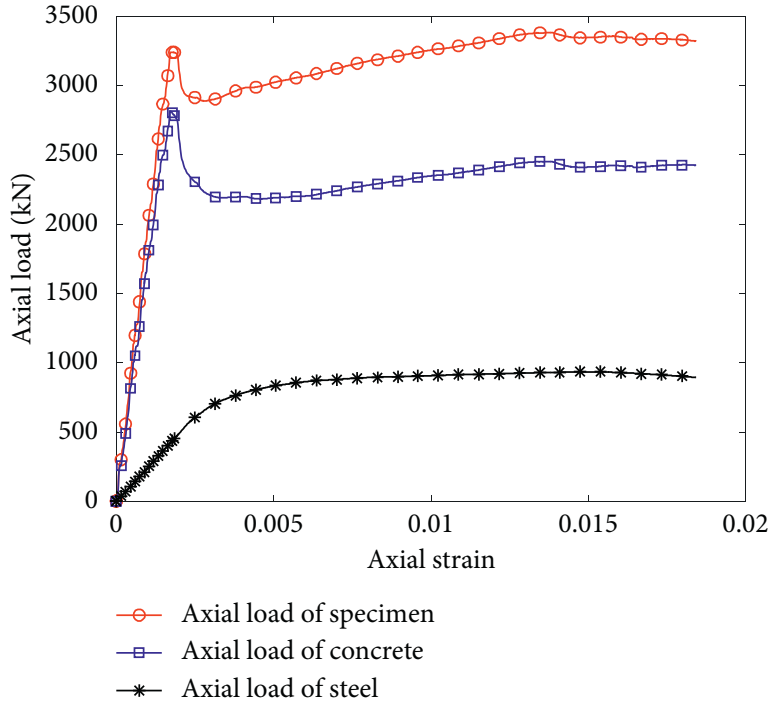

(a)

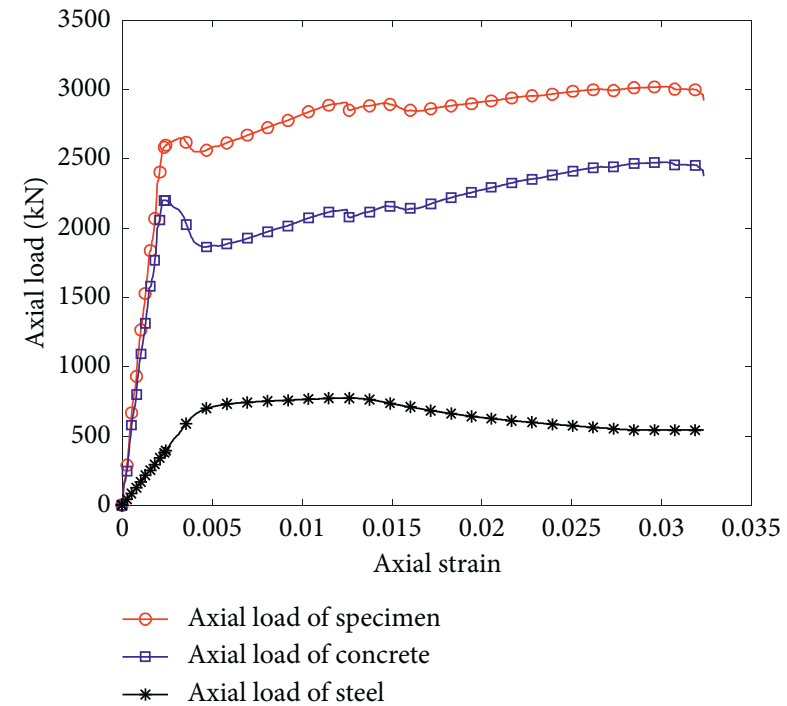

(b)

FIgURE 8: Axial load taken by the concrete and the steel tube. (a) RC1-ec1-F6 and (b) RC3-ec3-F6.

TABLE 4: Key test results.

\begin{tabular}{|c|c|c|c|c|c|c|}
\hline Specimen name & $P_{\max }(\mathrm{kN})$ & $f_{\mathrm{cc}}(\mathrm{MPa})$ & $\varepsilon_{\mathrm{cu}}(\%)$ & $\varepsilon_{\text {hrup }}(\%)$ & $f_{\mathrm{cc}} / f_{\mathrm{co}}$ & $\varepsilon_{\mathrm{cu}} / \varepsilon_{\mathrm{co}}$ \\
\hline RC1-ec1-F6 & 3384 & 49.9 & 1.84 & 0.60 & 1.0 & 7.1 \\
\hline RC2-ec2-F3 & 2763 & 45.9 & 2.01 & 0.54 & 0.9 & 7.7 \\
\hline RC2-ec2-F6 & 2916 & 46.2 & 2.17 & 0.65 & 0.9 & 8.4 \\
\hline RC3-ec3-F3 & 2784 & 57.0 & 1.94 & 0.96 & 1.1 & 7.5 \\
\hline RC3-ec3-F6 & 3023 & 66.2 & 3.23 & 1.32 & 1.3 & 12.4 \\
\hline RC4-ec4-F6 & 2254 & 61.4 & 2.54 & 1.22 & 1.2 & 9.8 \\
\hline RC1-rc1-F6 & 3648 & 54.5 & 1.22 & 0.36 & 1.1 & 4.7 \\
\hline $\mathrm{RC} 2-\mathrm{rc} 2-\mathrm{F} 3$ & 2907 & 52.7 & 1.33 & 0.27 & 1.0 & 5.1 \\
\hline RC2-rc2-F6 & 3700 & 64.8 & 2.29 & 1.04 & 1.3 & 8.8 \\
\hline RC3-rc3-F3 & 2750 & 60.0 & 1.39 & 1.22 & 1.2 & 5.3 \\
\hline RC3-rc3-F6 & 2868 & 62.0 & 2.16 & 0.95 & 1.2 & 8.3 \\
\hline RC4-rc4-F6 & 2340 & 66.2 & 2.87 & 1.05 & 1.3 & 11.0 \\
\hline RC1-F6 & 5846 & 65.5 & 2.18 & 1.86 & 1.3 & 8.4 \\
\hline RC2-F3 & 4751 & 64.0 & 1.19 & 0.92 & 1.3 & 4.6 \\
\hline RC2-F6 & 4561 & 61.4 & 1.61 & 1.08 & 1.2 & 6.2 \\
\hline RC3-F3 & 3799 & 64.1 & 0.70 & 0.83 & 1.3 & 2.7 \\
\hline RC3-F6 & 4169 & 70.4 & 1.38 & 0.85 & 1.4 & 5.3 \\
\hline RC4-F6 & 2806 & 63.4 & 1.65 & 1.03 & 1.3 & 6.4 \\
\hline
\end{tabular}

ascending curve until the final failure. As indicated in Table 4 , the average strength enhancement ratio $f_{\mathrm{cc}} / f_{\mathrm{co}}$ of these four specimens in Figure 9(b) is around 1.2, which are slightly smaller than corresponding R-CFFTs. As shown in Figure 9(a), RE-DSTCs display similar stress drop at the axial strain of around $0.30 \%$. Specimens RC3-ec3-F6 and RC4-ec4-F6 have higher axial stress and larger ultimate axial strain than specimens RC1-ec1-F6 and RC4-ec4-F6. As indicated in Table 4, specimens RC3-ec3-F6 and RC4-ec4-F6 also have higher strength enhancement ratio $f_{\mathrm{cc}} / f_{\mathrm{co}}$ and strain enhancement ratio $\varepsilon_{\mathrm{cu}} / \varepsilon_{\mathrm{co}}$ than specimens RC1-ec1-F6 and RC4-ec4-F6. It is evident that a larger aspect ratio will have no negative effect on the confinement effect in rectangular DSTCs. On the contrary, a rectangular DSTC with a larger aspect ratio generally has a larger ultimate axial strain and higher axial stress at the ultimate strain. This observation is inconsistent with the test observation for rectangular FRP-confined concrete columns made in $[28,29]$ that the confinement effect of the rectangular FRP tube decreases with the increase of the aspect ratio. As shown in Figure 5, with the increase of the aspect ratio, the concrete in the region $\mathrm{A}$ is under more effective confinement due to the local confinement effect provided by the steel tube and the FRP tube, leading to higher strength enhancement there.

3.5. Effect of FRP Thickness. As shown in Figure 10, six pairs of rectangular DSTCs, which have the same aspect ratio and the same void ratio but different FRP tube thicknesses, are compared to investigate the effect of FRP tube thickness. For 


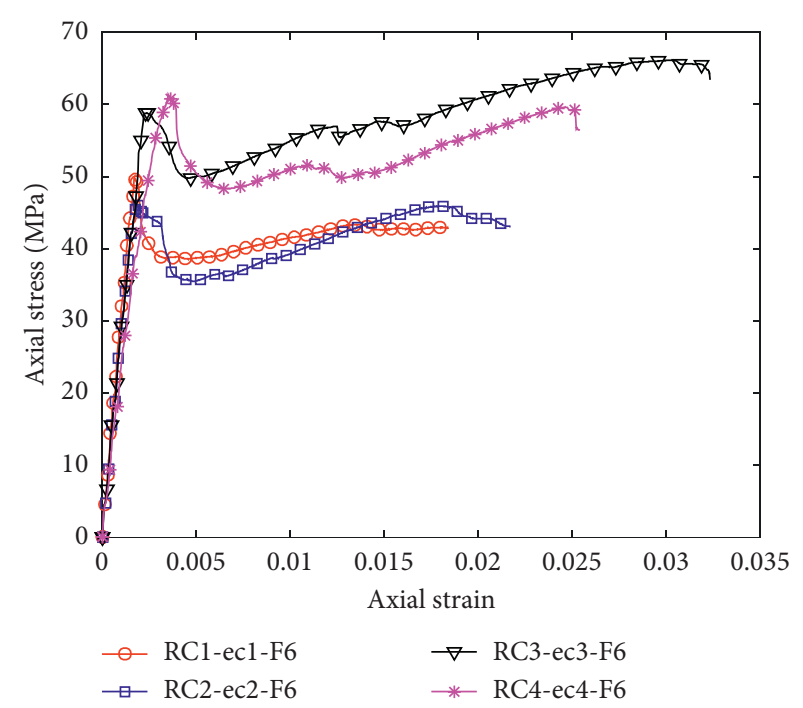

(a)

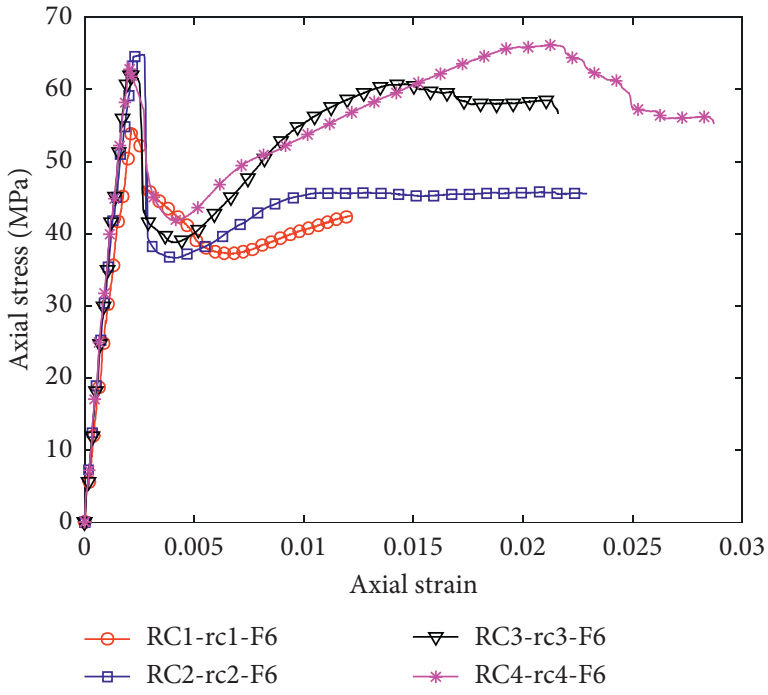

(b)

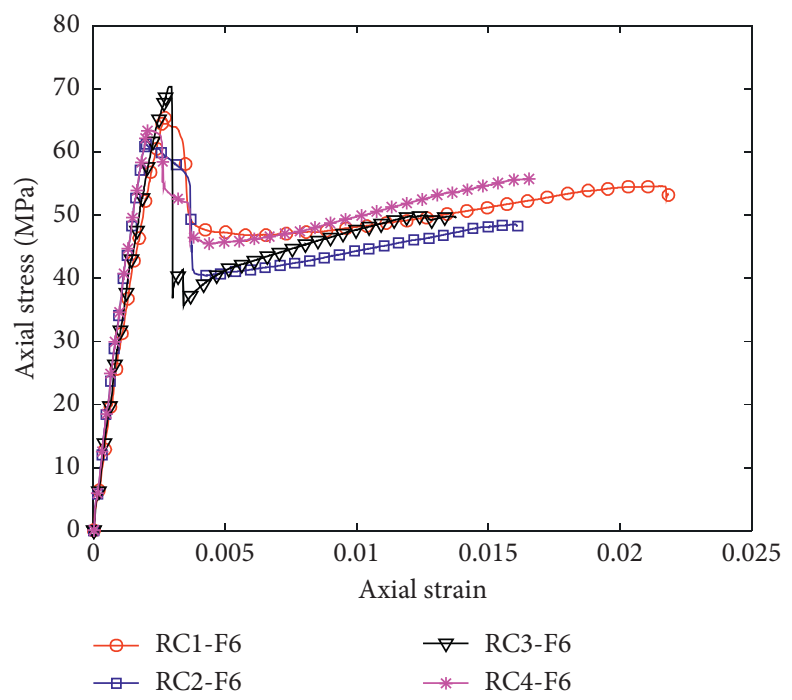

(c)

Figure 9: Effect of cross-sectional aspect ratio. (a) RE-DSTCs, (b) RR-DSTCs, and (c) R-FCSCs.

FRP-confined concrete columns, the axial stress-strain behavior of the confined concrete is significantly affected by the confinement stiffness and the hoop rupture strain of the FRP tube $[27,35,36]$. As shown in Table 4 , the strength enhancement ratio $f_{\mathrm{cc}} / f_{\mathrm{co}}$ and the strain enhancement ratio $\varepsilon_{\mathrm{cu}} / \varepsilon_{\mathrm{co}}$ of rectangular DSTCs with a 6-layer FRP tube are much higher than those of corresponding specimens with a 3-layer FRP tube. As shown in Figure 10, a thicker FRP tube generally leads to a larger stiffness for the second branch of the axial stress-strain curves, a larger strength enhancement ratio, and a larger ductility enhancement ratio.

3.6. Effect of Cross Section of Inner Steel Tube. Six pairs of rectangular DSTCs are compared in Figure 11 to evaluate the effect of the cross sectional shape of the inner steel tube. The axial stress-strain curves of R-CFFTs are also included in Figure 11 for comparison. It is evident that the axial stress- axial strain curves of R-CFFTs have an initial linear ascending branch and then a severe axial stress drop at the axial strain of around $0.30 \%$, followed by an ascending branch until the final failure. This phenomenon is consistent with the observation in [30], which is believed to be associated with the brittle nature of the concrete when the confinement is insufficient. For RE-DSTCs, the axial stressstrain curves have an initial ascending branch and then a fluctuation/drop in the axial stress, followed by a second ascending branch. In contrast, RR-DSTCs experienced a sudden drop in the axial stress starting right at the transition point at their axial stress-strain curves. The sudden drop in the axial stress of RR-DSTCs is smaller than that of corresponding R-CFFTs but much larger than that of corresponding RE-DSTCs. Therefore, the confinement effect of RR-DSTCs is less efficient than that of RE-DSTCs. For REDSTCs, their cross section can be regarded as two arcs due to the existence of the elliptical steel tube. The arc effect may 


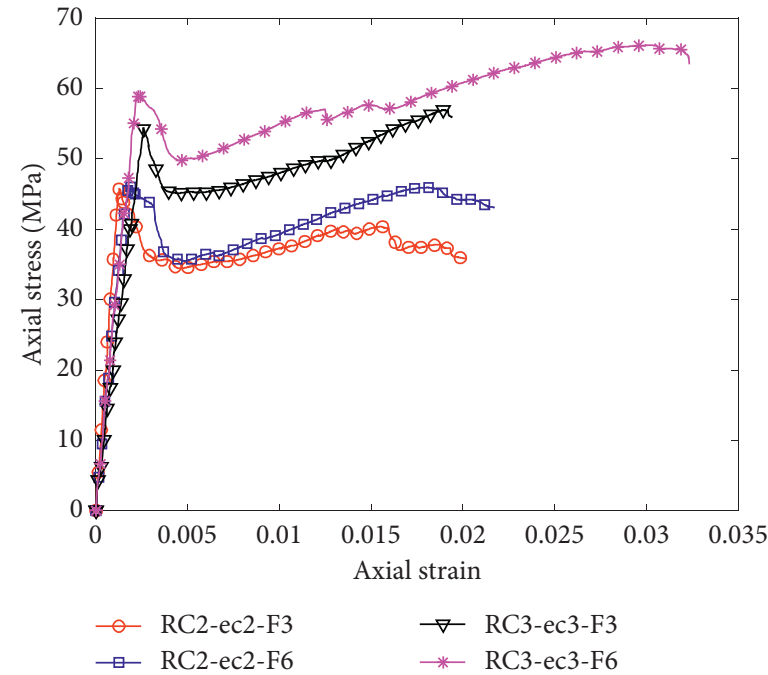

(a)

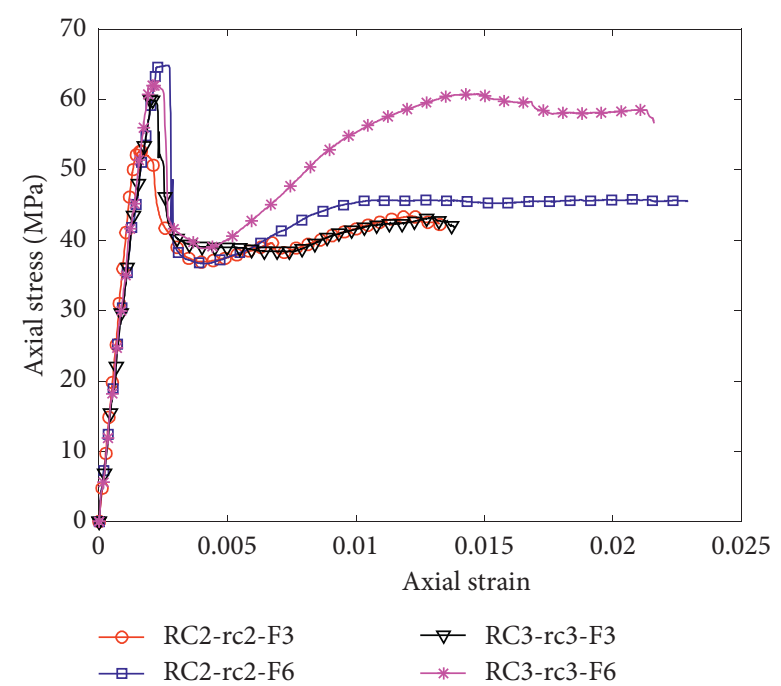

(b)

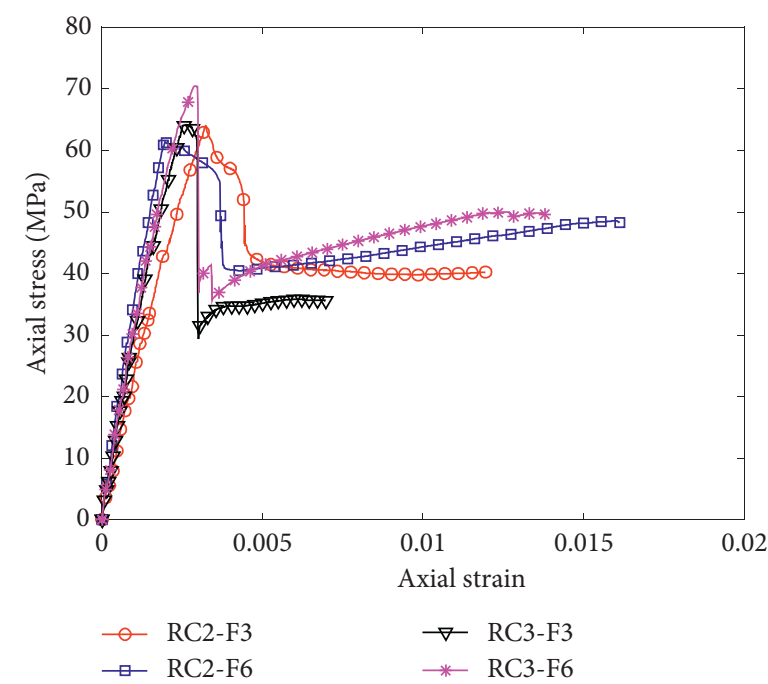

(c)

Figure 10: Effect of FRP tube thickness. (a) RR-DSTCs, (b) RE-DSTCs, and (c) R-FCSCs.

exist on the cross section of RE-DSTCs when the concrete layer is under axial compression and under the confinement of the FRP tube, leading to better performance than RRDSTCs. It is evident that the cross sectional shape of the inner steel tube has a significant effect on the axial stressstrain behavior of the confined concrete in rectangular DSTCs. As illustrated in Figure 11 and Table 4, rectangular DSTCs with an elliptical steel tube generally have better ductility than corresponding specimens with a rectangular steel tube.

\section{Comparisons with Stress-Strain Model}

Lam and Teng [35] developed a stress-strain model for circular FRP-confined concrete columns, in which a number of important issues including the actual hoop rupture strain, the effect of the hoop stiffness, and the sufficiency of the FRP tube were carefully examined. Based on the model for circular FRP-confined concrete columns, Lam and Teng [27] further developed a stress-strain model for rectangular FRPconfined concrete columns, in which the aspect ratio of the rectangular cross section was considered. In 2009, Teng et al. [36] refined Lam and Teng's [35] model for circular FRPconfined concrete columns, in which more accurate expressions for the ultimate axial strain and the compressive strength were employed. Based on Teng et al.'s [36] model for circular FRP-confined concrete, Yu et al. [10] proposed a simple stress-strain model for the confined concrete in circular DSTCs with a circular inner steel tube. The effect of the inner void in circular DSTCs was considered for the ultimate axial strain of the concrete using the void ratio $\varphi$, which was defined as the ratio of the steel tube diameter to the outer diameter of the circular concrete section. In 2013, $\mathrm{Yu}$ and Teng [19] conducted an experimental study on hybrid DSTCs with a square outer FRP tube and a circular inner steel tube. Based on the experimental results in $\mathrm{Yu}$ and Teng [19], a stress-strain model for concrete in square DSTCs was proposed by combining Lam and Teng's [27] 

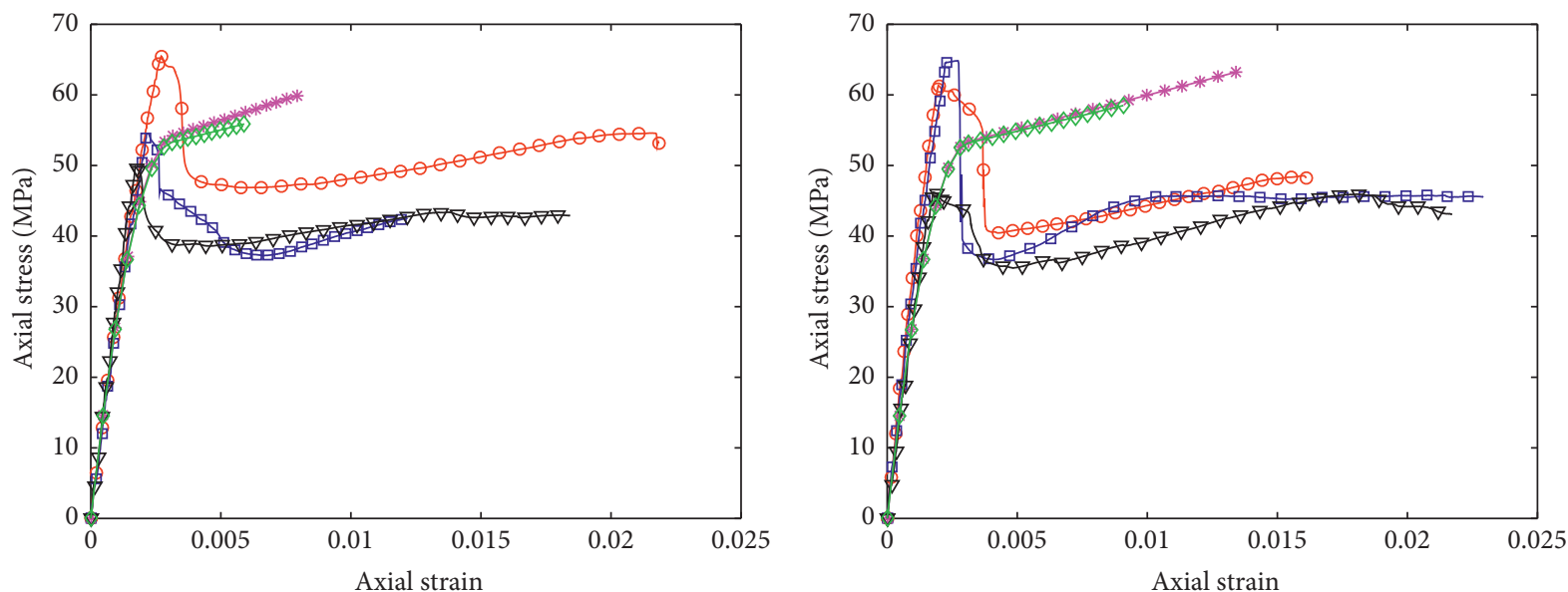

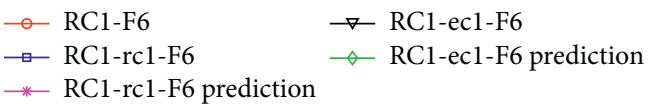

(a)

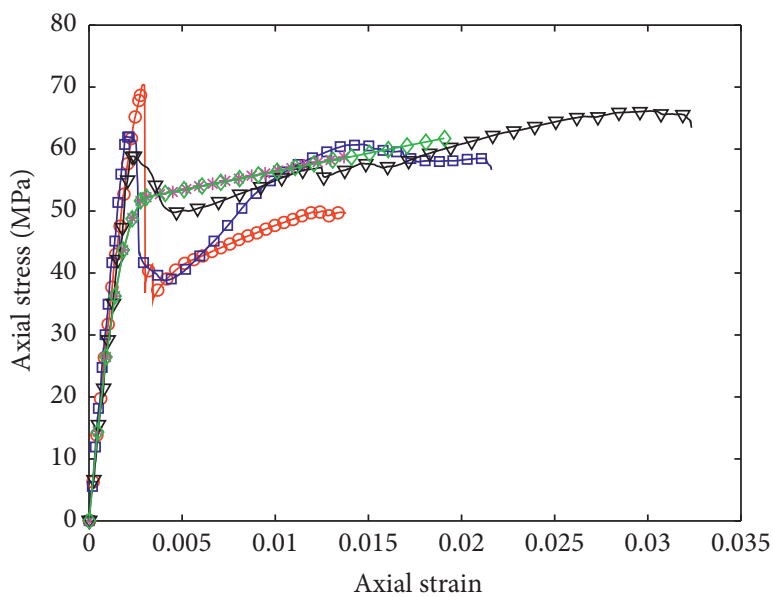

$\because \mathrm{RC} 3-\mathrm{rc} 3-\mathrm{F} 6$
$\rightarrow \mathrm{RC} 3-\mathrm{rc} 3-\mathrm{F} 6$ prediction

(c)

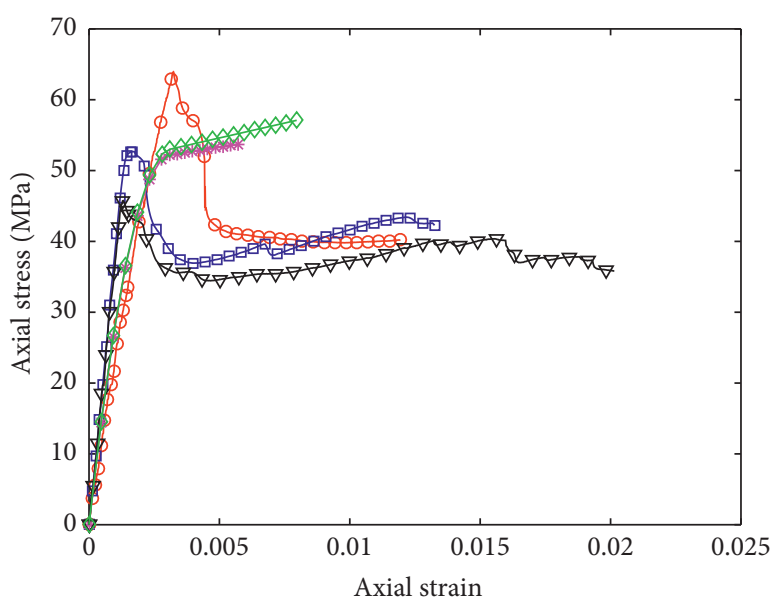

○ RC2-F6 $\rightarrow$ RC2-ec2-F6

$\rightarrow$ RC2-rc2-F6 $\rightarrow$ RC2-ec2-F6 prediction

$*$ RC2-rc2-F6 prediction

(b)

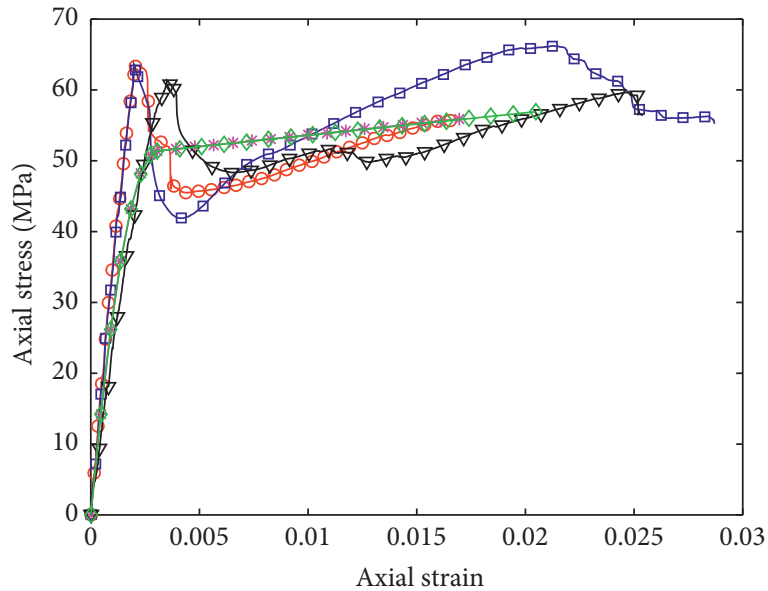

- RC4-F6 $\quad \rightarrow$ RC4-ec4-F6

$\rightarrow$ RC4-rc4-F6 $\rightarrow$ RC4-ec4-F6 prediction

* RC4-rc4-F6 prediction

(d)

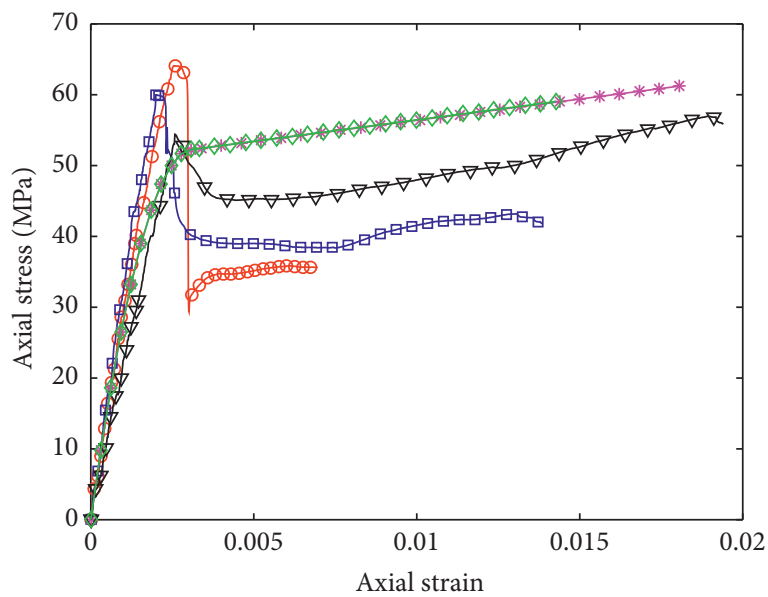

$\begin{array}{ll}\rightarrow \text { RC3-F3 } & \nabla \text { RC3-ec3-F3 } \\ \rightarrow-\text { RC3-rc3-F3 } & \succ \text { RC3-ec3-F3 prediction } \\ \rightarrow-\text { RC3-rc3-F3 prediction } & \end{array}$

(f) (e)

$$
\begin{aligned}
& \rightarrow \text { RC2-ec2-F3 } \\
& \rightarrow-\text { RC2-ec2-F3 prediction }
\end{aligned}
$$

FIGURE 11: Effect of inner steel tubes. 
model for rectangular FRP-confined concrete and Yu et al.'s [10] model for circular DSTCs with a circular inner steel tube. This model also adopted Lam and Teng's [27] equations to consider the effect of the aspect ratio of the rectangular cross section.

$\mathrm{Yu}$ and Teng's [19] model consists of a parabolic first portion and a linear second portion for the stress-strain curve of confined concrete in hybrid DSTCs:

$$
\begin{aligned}
& \sigma_{c}=E_{c} \varepsilon_{c}-\frac{\left(E_{c}-E_{2 c}\right)^{2}}{4 f_{o}} \varepsilon_{c}^{2} \cdot 0 \leq \varepsilon_{c} \leq \varepsilon_{t}, \\
& \sigma_{c}=f_{o}+E_{2 c} \varepsilon_{c} \cdot \varepsilon_{t} \leq \varepsilon_{c} \leq \varepsilon_{c u},
\end{aligned}
$$

where $\sigma_{c}$ and $\varepsilon_{c}$ are the axial stress and the axial strain of confined concrete, respectively; $f_{o}$ is the intercept of the stress axis by the linear second portion, which is taken to be $f_{c o}^{\prime} ; E_{c}$ is the initial elastic modulus of confined concrete; $E_{2 c}$ is the slope of the linear second portion of the stress-strain curve; $\varepsilon_{\mathrm{cu}}$ is the ultimate axial strain of confined concrete; and $\varepsilon_{t}$ is the axial strain at the smooth transition point where the parabolic first portion meets the linear second portion.

The parabolic first portion and the linear second portion are connected with a smooth transition at the transition strain $\varepsilon_{t}$ :

$$
\varepsilon_{t}=\frac{2 f_{o}}{E_{c}-E_{2 c}}
$$

The slope of the linear second portion of the stress-strain curve $E_{2 c}$ is given by

$$
E_{2 c}=\frac{f_{\mathrm{cc}}^{\prime}-f_{o}}{\varepsilon_{\mathrm{cu}}},
$$

where $f_{c c}^{\prime}$ is the compressive strength of confined concrete.

The compressive strength $f_{c c}^{\prime}$ and the ultimate axial strain $\varepsilon_{\mathrm{cu}}$ of confined concrete are shown in equations (4) and (5). The effect of the aspect ratio for the rectangular cross section is considered for $f_{\mathrm{cc}}^{\prime}$ and $\varepsilon_{\mathrm{cu}}$ using the cross-sectional shape factor for the strength enhancement $k_{s 1}$ and the crosssectional shape factor for the strain enhancement $k_{s 2}$. The void area ratio $\varphi_{A}$ (i.e., the ratio of the concrete void area to the area of the gross rectangular concrete section), rather than the void ratio $\varphi$ (i.e., the ratio of the steel tube diameter to the outer diameter of the circular concrete section), was used in Yu and Teng's [19] model:

$$
\begin{aligned}
& \frac{f_{\mathrm{cc}}^{\prime}}{f_{\mathrm{co}}^{\prime}}= \begin{cases}1+3.5 k_{s 1}\left(\rho_{K}-0.01\right) \rho_{\varepsilon}, & \rho_{K} \geq 0.01, \\
1, & \rho_{K}<0.01,\end{cases} \\
& \frac{\varepsilon_{\mathrm{cu}}}{\varepsilon_{\mathrm{co}}}=1.75+6.5 k_{s 2} \rho_{K}^{0.8} \rho_{\varepsilon}^{1.45}\left(1-\sqrt{\varphi_{A}}\right)^{-0.22}, \\
& \varphi=\sqrt{\varphi_{A}}, \\
& \rho_{K}=\frac{E_{\mathrm{frp}} t_{\mathrm{frp}}}{E_{\mathrm{seco}} R_{o}},
\end{aligned}
$$

$$
\begin{array}{r}
\rho_{\varepsilon}=\frac{\varepsilon_{h, \text { rup }}}{\varepsilon_{\mathrm{co}}}, \\
E_{\text {seco }}=\frac{f_{\mathrm{co}}^{\prime}}{\varepsilon_{\mathrm{co}}},
\end{array}
$$

where $f_{\text {co }}^{\prime}$ and $\varepsilon_{\text {co }}$ are the compressive strength and the axial strain at peak axial stress of unconfined concrete, respectively; $\varphi$ is the void ratio for circular DSTCs with a circular inner steel tube, which is defined as the ratio of the steel tube diameter to the outer diameter of the circular concrete section; $\varphi_{A}$ is the void area ratio for square and rectangular DSTCs, which is defined as the ratio of the concrete void area to the area of the gross concrete section; $\rho_{K}$ and $\rho_{\varepsilon}$ are the confinement stiffness ratio and the strain ratio, respectively; $E_{\text {seco }}$ is the secant modulus of unconfined concrete; $E_{\text {frp }}$ is the elastic modulus of FRP in the hoop direction; $t_{\text {frp }}$ is the thickness of the FRP tube; and $\varepsilon_{h \text {,rup }}$ is the hoop strain of FRP at the rupture of the tube due to hoop tensile stresses.

The cross-sectional shape factors $k_{s 1}$ and $k_{s 2}$ for rectangular FRP-confined concrete columns in Lam and Teng's [27] model are given by equations (10) and (11). For hybrid DSTCs with a square cross section, $k_{s 1}$ and $k_{s 2}$ are the same as used in Yu and Teng's [19] model. In the following predictions, $k_{s 1}$ and $k_{s 2}$ from Lam and Teng's [27] model are employed to consider the effect of the cross-sectional aspect ratio:

$$
\begin{aligned}
& k_{s 1}=\left(\frac{b}{h}\right)^{2} \frac{A_{e}}{A_{c}} \\
& k_{s 1}=\left(\frac{h}{b}\right)^{2} \frac{A_{e}}{A_{c}} \\
& \frac{A_{e}}{A_{c}}=\frac{1-\left((b / h)\left(h-2 R_{c}\right)^{2}+(h / b)\left(b-2 R_{c}\right)^{2}\right) / 3 A_{g}-\rho_{\mathrm{sc}}}{1-\rho_{\mathrm{sc}}} \\
& A_{g}=b h-(4-\pi) R_{c}^{2},
\end{aligned}
$$

where $b$ and $h$ are the width (the shorter side) and the breadth (the longer side) of the rectangular cross section, respectively; $R_{o}$ is the outer radius of the circular section of concrete for circular DSTCs, which is taken as $\sqrt{b h / \pi}$ for rectangular DSTCs in the present study; $A_{e} / A_{c}$ is the effective confinement area ratio for rectangular FRP-confined concrete columns; $A_{g}$ is the gross area of the rectangular column section; and $\rho_{\mathrm{sc}}$ is the cross-sectional area ratio of the longitudinal steel reinforcement.

The test results from the present study are compared with Yu and Teng's [19] model in Figures 11 and 12. Due to the existence of the axial stress drop at the axial strain of around $0.30 \%$, Yu and Teng's [19] model could not capture the complicated shape of the axial stress-strain curves of rectangular DSTCs. However, Yu and Teng's [19] model generally provides close predictions for the peak axial stress of the confined concrete in rectangular DSTCs 


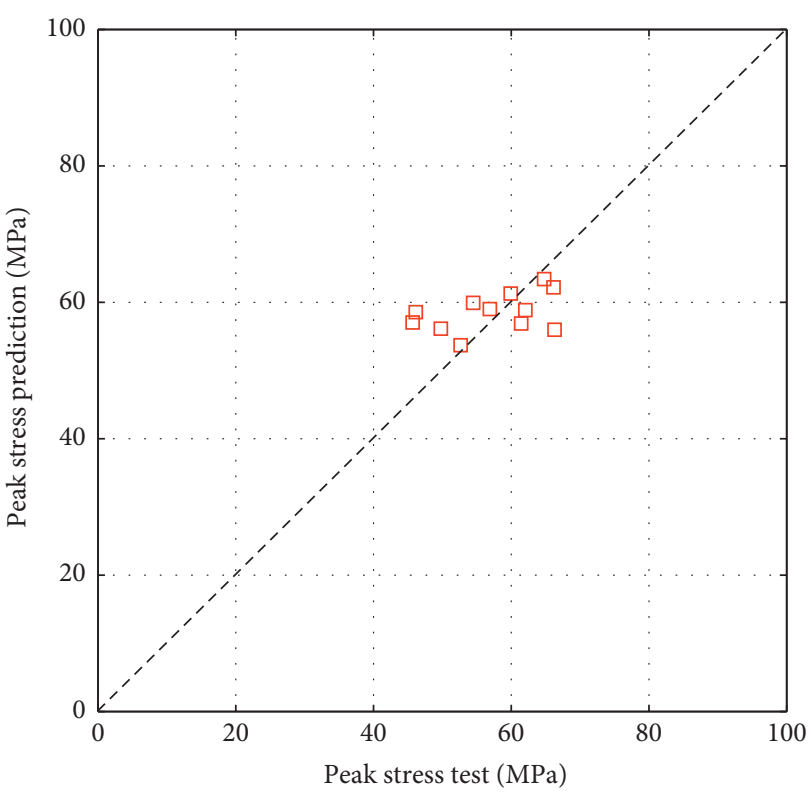

(a)

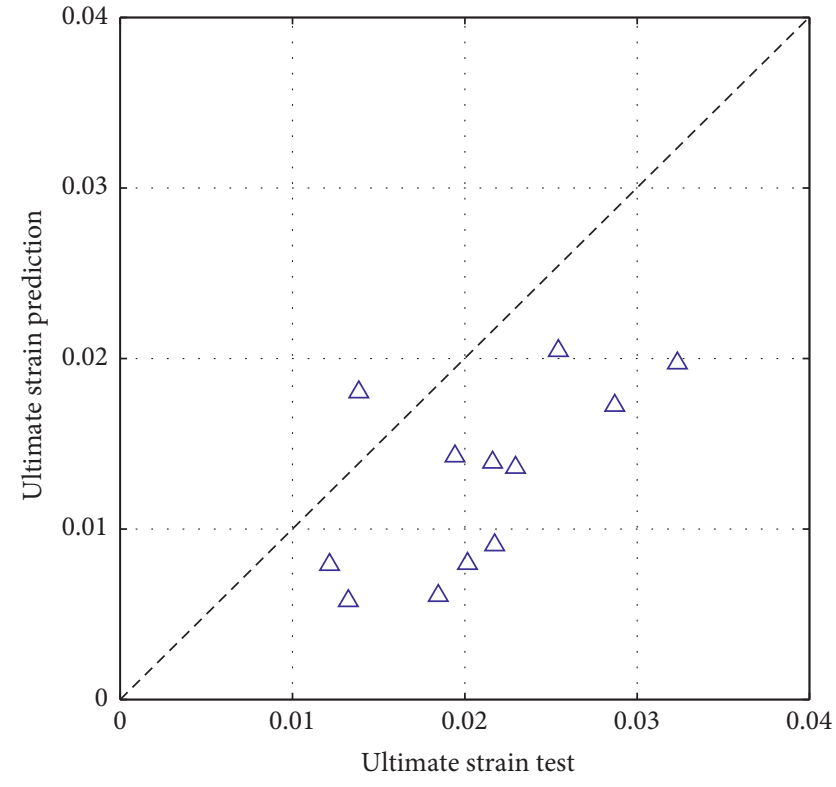

(b)

Figure 12: Comparisons with Yu and Teng's [19] model. (a) Peak stress and (b) ultimate strain.

(Figure 12(a)). As shown in Figures 11 and 12(b), Yu and Teng's [19] model yields conservative predictions for the ultimate axial strain of the confined concrete in rectangular DSTCs. Yu and Teng's [19] model, which was originally based on Lam and Teng's [27] model for rectangular FRPconfined concrete and Yu et al.'s [10] model for circular DSTCs with a circular inner steel tube, does not consider the complicated mechanism in such rectangular DSTCs. Further research is needed for the development of a more reliable stress-strain model for the confined concrete in rectangular DSTCs when more test data are available. Such a stressstrain model should take due account of various factors, including the cross-sectional aspect ratio, the void area ratio, the thickness of the steel tube, and the cross-sectional shape of the inner steel tube.

\section{Conclusions}

This paper presents an experimental study on rectangular DSTCs under axial compression. The test results and discussions allow the following conclusions to be drawn:

(1) A larger aspect ratio will have no negative effect on the confinement effect in rectangular DSTCs. A rectangular DSTC with a larger cross-sectional aspect ratio generally has a larger ultimate axial strain and higher axial stress at the ultimate axial strain.

(2) Rectangular DSTCs with an elliptical steel tube exhibit better performance than corresponding specimens with a rectangular steel tube.

(3) Rectangular DSTCs with a thicker FRP tube generally have a larger stiffness for the second branch of the axial stress-strain curve, a larger strength enhancement ratio, and a ductility enhancement ratio.
(4) Yu and Teng's model generally provides close predictions for the peak axial stress of the confined concrete but yields conservative predictions for the ultimate axial strain of the confined concrete in rectangular DSTCs.

\section{Data Availability}

All tests were conducted by the authors. Resuests for data, 12 months after publication of this article, will be considered by the corresponding author.

\section{Conflicts of Interest}

The authors declare that they have no conflicts of interest.

\section{Acknowledgments}

The authors are grateful for the financial support received from the National Natural Science Foundation of China (grant nos. 51978332 and 51608263) and the Natural Science Foundation of Jiangsu Province (grant no. BK20160998).

\section{References}

[1] L. C. Hollaway and J. G. Teng, Strengthening and Rehabilitation of Civil Infrastructures Using Fibre Reinforced Polymer (FRP) Composites, Woodhead Publishing, Cambridge, UK, 2008.

[2] J.-J. Xu, Z.-P. Chen, Y. Xiao, C. Demartino, and J.-H. Wang, "Recycled aggregate concrete in FRP-confined columns: a review of experimental results," Composite Structures, vol. 174, pp. 277-291, 2017.

[3] Y. Wang, G. Cai, Y. Li, D. Waldmann, A. Si Larbi, and K. D. Tsavdaridis, "Behavior of circular fiber-reinforced polymer-steel-confined concrete columns subjected to 
reversed cyclic loads: experimental studies and finite-element analysis," Journal of Structural Engineering, vol. 145, no. 9, Article ID 04019085, 2019.

[4] J. G. Teng, "New-material hybrid structures," China Civil Engineering Journal, vol. 51, no. 12, pp. 1-11, 2008, in Chinese.

[5] J. G. Teng, T. Yu, Y. L. Wong, and S. L. Dong, "Hybrid FRPconcrete-steel tubular columns: concept and behavior," Construction and Building Materials, vol. 21, no. 4, pp. 846854, 2007.

[6] B. Zhang, J. G. Teng, and T. Yu, "Experimental behavior of hybrid FRP-concrete-steel double-skin tubular columns under combined axial compression and cyclic lateral loading," Engineering Structures, vol. 99, pp. 214-231, 2015.

[7] I. A. Omar, M. A. ElGawady, G. Ahmed, A. Sujith, and A. Mohanad, "Seismic performance of innovative hollow-core FRP-concrete-steel bridge columns," Journal of Bridge Engineering, vol. 22, no. 2, p. 04016120, 2017.

[8] L.-H. Han, Z. Tao, F.-Y. Liao, and Y. Xu, "Tests on cyclic performance of FRP-concrete-steel double-skin tubular columns," Thin-Walled Structures, vol. 48, no. 6, pp. 430-439, 2010.

[9] L. C. Hollaway, "A review of the present and future utilisation of FRP composites in the civil infrastructure with reference to their important in-service properties," Construction and Building Materials, vol. 24, no. 12, pp. 2419-2445, 2010.

[10] T. Yu, J. G. Teng, and Y. L. Wong, "Stress-strain behavior of concrete in hybrid FRP-concrete-steel double-skin tubular columns," Journal of Structural Engineering, vol. 136, no. 4, pp. 379-389, 2010.

[11] B. Zhang, J.-L. Zhao, T. Huang, N.-Y. Zhang, Y.-J. Zhang, and X.-M. Hu, "Effect of fiber angles on hybrid fiber-reinforced polymer-concrete-steel double-skin tubular columns under monotonic axial compression," Advances in Structural Engineering, 2020.

[12] B. Zhang, J. G. Teng, and T. Yu, "Compressive behavior of double-skin tubular columns with high-strength concrete and a filament-wound FRP tube," Journal of Composites for Construction-ASCE.

[13] T. Yu, B. Zhang, Y. B. Cao, and J. G. Teng, "Behavior of hybrid FRP-concrete-steel double-skin tubular columns subjected to cyclic axial compression," Thin-Walled Structures, vol. 61, pp. 196-203, 2012.

[14] T. Ozbakkaloglu and E. Akin, "Behavior of FRP-confined normal- and high-strength concrete under cyclic axial compression," Journal of Composites for Construction, vol. 16, no. 4, pp. 451-463, 2012.

[15] P. Xie, "Behavior of large-scale hybrid FRP-concrete-steel double-skin tubular columns subjected to concentric and eccentric compression," PhD Thesis, The Hong Kong Polytechnic University, Hong Kong, China, 2018.

[16] T. Yu, Y. L. Wong, and J. G. Teng, "Behavior of hybrid FRPconcrete-steel double-skin tubular columns subjected to eccentric compression," Advances in Structural Engineering, vol. 13, no. 5, pp. 961-974, 2010.

[17] R. Wang, L.-H. Han, and Z. Tao, "Behavior of FRP-concretesteel double skin tubular members under lateral impact: experimental study," Thin-Walled Structures, vol. 95, pp. 363-373, 2015.

[18] I. A. Omar and M. A. ElGawady, "Performance of hollow-core FRP-concrete-steel bridge columns subjected to vehicle collision," Engineering Structures, vol. 123, pp. 517-531, 2016.

[19] T. Yu and J. G. Teng, "Behavior of hybrid FRP-concrete-steel double-skin tubular columns with a square outer tube and a circular inner tube subjected to axial compression," Journal of Composites for Construction, vol. 17, no. 2, pp. 271-279, 2012.
[20] T. Ozbakkaloglu, B. A. L. Fanggi, and J. Zheng, "Confinement model for concrete in circular and square FRP-concrete-steel double-skin composite columns," Materials \& Design, vol. 96, pp. 458-469, 2016.

[21] B. A. L. Fanggi and T. Ozbakkaloglu, "Effect of inner steel tube cross-sectional shape on compressive behavior of square FRPconcrete-steel double-skin tubular columns," Applied Mechanics and Materials, vol. 752-753, pp. 578-583, 2014.

[22] B. A. L. Fanggi and T. Ozbakkaloglu, "Influence of inner steel tube diameter on compressive behavior of square FRP-HSCsteel double-skin tubular columns," Advanced Materials Research, vol. 1119, pp. 688-693, 2015.

[23] B. Zhang, W. Wei, G. S. Feng, Q. B. Zhang, N. Y. Zhang, and X. M. Hu, "Experimental study of rectangular FRP-concretesteel double-skin tubular column under axial compression," Industrial Construction, vol. 49, no. 12, pp. 195-200, 2019, in Chinese.

[24] X. Li, J. Lu, D.-D. Ding, and W. Wang, "Axial strength of FRPconfined rectangular RC columns with different cross-sectional aspect ratios," Magazine of Concrete Research, vol. 69, no. 19, pp. 1011-1026, 2017.

[25] H. Toutanji, M. Han, J. Gilbert, and S. Matthys, "Behavior of large-scale rectangular columns confined with FRP composites," Journal of Composites for Construction, vol. 14, no. 1, pp. 62-71, 2009.

[26] T. Ozbakkaloglu and D. J. Oehlers, "Concrete-filled square and rectangular FRP tubes under axial compression," Journal of Composites for Construction, vol. 12, no. 4, pp. 469-477, 2008.

[27] L. Lam and J. G. Teng, "Design-oriented stress-strain model for FRP-confined concrete in rectangular columns," Journal of Reinforced Plastics and Composites, vol. 22, no. 13, pp. 1149-1186, 2003.

[28] H.-X. Liu, G.-J. Liu, X.-Z. Wang, and X.-Q. Kong, "Effect of cross-sectional aspect ratio and basalt fiber-reinforced polymer-confined number on axial compression behavior of short columns," Journal of Reinforced Plastics and Composites, vol. 34, no. 10, pp. 782-794, 2015.

[29] Y.-F. Wu and Y.-Y. Wei, "Effect of cross-sectional aspect ratio on the strength of CFRP-confined rectangular concrete columns," Engineering Structures, vol. 32, no. 1, pp. 32-45, 2010.

[30] T. Ozbakkloglu, "Ultra-high-strength concrete-filled FRP tubes: compression tests on square and rectangular columns," Key Engineering Materials, vol. 575, pp. 239-244, 2014.

[31] G. Cavill and T. Yu, "Rectangular hybrid FRP-concrete-steel double-skin tubular columns: stub column tests," in Proceedings of the 23rd Australasian Conference on the Mechanics of Structures and Materials (ACMSM23), pp. 521-526, Bryon Bay, Australia, December 2014.

[32] ASTM C39/C39M, Standard Test Method for Compressive Strength of Cylindrical Concrete Specimens, American Society for Testing and Materials, Philadelphia, PA, USA, 2008.

[33] ASTM D3039/D3039M, Standard Test Method for Tensile Properties of Polymer Matrix Composite Materials, American Society for Testing and Materials, Philadelphia, PA, USA, 2017.

[34] BS 18, Tensile Testing of Metals (Including Aerospace Materials), British Standards Institution, London, UK, 1987.

[35] L. Lam and J. G. Teng, "Design-oriented stress-strain model for FRP-confined concrete," Construction and Building Materials, vol. 17, no. 6-7, pp. 471-489, 2003.

[36] J. G. Teng, T. Jiang, L. Lam, and Y. Z. Luo, "Refinement of a design-oriented stress-strain model for FRP-confined concrete," Journal of Composites for Construction, vol. 13, no. 4, pp. 269-278, 2009. 